\title{
Mechanism of Interannual Variability of Ocean Bottom Pressure in the South Pacific
}

\author{
Xuhua Cheng \\ Hohai University \\ Chengcheng Yang \\ Hohai University \\ Niansen Ou \\ Guangdong Ocean University \\ Xiaoqin Xiong \\ Hohai University
}

Jianhuang Qin ( $\nabla$ qinjianhuang@163.com )

Hohai University https://orcid.org/0000-0003-4536-7992

\section{Research Article}

Keywords: ocean bottom pressure (OBP), southeastern Pacific, sea level pressure (SLP), El NiñoSouthern Oscillation (ENSO)

Posted Date: July 6th, 2021

DOl: https://doi.org/10.21203/rs.3.rs-559761/v1

License: (c) (i) This work is licensed under a Creative Commons Attribution 4.0 International License. Read Full License

Version of Record: A version of this preprint was published at Climate Dynamics on February 25th, 2022. See the published version at https://doi.org/10.1007/s00382-022-06198-0. 


\section{Abstract}

The study of ocean bottom pressure (OBP) is useful for understanding the barotropic processes variability that contribute to sea level rise. Previous studies have reported the strong OBP anomalies in the Southern Ocean on different time scales. In this study, the characteristic and mechanisms of the energetic interannual OBP variability in the southeastern Pacific are examined using 14 years of GRACE data. It is found that the OBP anomalies are positive (negative) related to the convergence (divergence) of Ekman transport forced by local winds variability. The sea level pressure (SLP) anomalies shows a wavenumber-3 structure in the high latitude of the South Pacific, which benefits a strong and persistent anticyclone over the southeastern Pacific, leading to the positive OBP anomalies there. Such SLP anomalies are similar to the second Pacific-South American (PSA2). Moreover, El Niño-Southern Oscillation (ENSO) plays an important role in the austral spring (August-November) OBP variability and leads the austral autumn (March-June) OBP variability by 1 season. These results highlight the influence of atmospheric variability on OBP anomalies and are validated by a mass conservation (non-Boussinesq) ocean model, which is expected to not only better understanding of OBP mechanisms in a longer time, but also predict OBP variation in the global scale.

\section{Introduction}

Sea level rise is the increasing level of the oceans under the effects of global warming, which poses a serious threat to coastal life around the world. Sea level variability is mainly consisted of two factors: one is the steric component, considered as an indicator for how the ocean heat content changes the sea surface height over time. The other is the ocean bottom pressure (OBP) associated with the pressure exerted on the ocean floor by the water column and the overlying atmosphere. The OBP helps to understand the nature of a similar signal in sea level anomaly, which is related to water mass change (Cazenave and Nerem, 2004; Chambers, 2006a). For instance, the OBP trend accounts for $69 \%$ global sea level rise over 2005-2014 (Chambers et al., 2016). Thus, any insight into OBP variability and their relation to sea level variability is expected to better understanding the vertical structure of oceanic variability, meridional overturning circulation, deep water formation and global climate system.

OBP is the vertical integral of atmosphere and sea water mass. Its variability is mainly induced by local mass redistribution as a result of changes in ocean circulation driven by winds (Gill and Niller, 1973), the global hydrological cycle including the loss of glaciers and runoffs (e.g., Chambers et al., 2004) and atmospheric pressure variability over the ocean (Ponte, 1999). The former is known as the dominant factor in local OBP variability on synoptic-interannual timescales, for instance in North Pacific and North Atlantic (e.g. Stepanov and Hughes, 2006; Cheng et al., 2013).

Due to the paucity of observations, researches of OBP were dependent on theoretical diagnosis and numerical models in the last century (e.g., Gill and Niller, 1973; Ponte, 1999). Since 2002, the launch of the Gravity Recovery and Climate Experiment (GRACE) provides an entirely new tool for monitoring global ocean mass variability (Tapley et al., 2004; Chambers, 2006b), for instance, mass loss from the 
Greenland and Antarctic ice sheets (Velicogna, 2009), and global scale sea level change (Willis et al., 2008). To date, the accumulated GRACE record during 2003-2016 provides an unprecedented view of global scale OBP variability, which can advance our process understanding of global sea level height, steric height and Antarctic ice sheet (e.g. Piecuch et al. 2013; Ren et al. 2013; Simpson et al. 2014; Storto et al. 2015; Volkov et al. 2015; Srinivasu et al. 2017).

Using GRACE observations, the long-term trend and interannual variability of OBP have been examined in global ocean (Johnson and Chambers, 2013), especially in the North Pacific (Song and Zlotnicki, 2008; Chambers, 2011; Cheng et al., 2013). In the Southern Ocean, a number of previous studies have used GRACE OBP gauges to infer gradients of pressure across major currents, such as the volume transport variations of the Antarctic Circumpolar Current (e.g., Zlotnicki et al., 2007; Makowski et al., 2015). The variations in the sea level and OBP in South Atlantic have been explained by basin-wide Sverdrup transport driven by local wind stress (Cabanes et al. 2006). Boening et al. (2011) reported a record-high OBP signal in the southeastern Pacific, and investigated the mechanisms caused by wind stress curl associated with a strong and persistent anticyclone. Quinn and Ponte (2012) suggested that the observed intraseasonal sea level related to OBP are significantly coherent with total sea level at high latitudes in the Southern Ocean. Ponte and Piecuch (2014) revealed that the strong OBP variability in the AustralianAntarctic and Bellingshausen Basins are partly related to enhanced local wind curl forcing and weakened gradients in the ratio of ocean depth and the Coriolis parameter. These results are consistent with the classic theory of Gill and Niiler (1973), that is, the OBP variability is the barotropic response to changes in the wind stress, ultimately resulting in sea level height variability. Overall, the mechanism of OBP variability in the Southern Ocean and its relation to sea level remain an interesting issue, and has not been fully investigated.

El Niño-Southern Oscillation (ENSO) teleconnection contains both atmospheric and oceanic variables, especially the sea level pressure (SLP) (Bjerknes, 1969) and sea surface temperature (SST) (Horel and Wallance, 1981). However, less attention of ENSO-related teleconnection studies has been given to OBP, which represents the barotropic dynamics of ocean. Cazenave et al. (2012) found that the positive global mean sea level anomaly during ENSO is attribute to ocean mass rather than thermal expansion increase. Song and Zlotnicki (2008) found a strong dipole of OBP in North Pacific during the ENSO events. They further examined the possible mechanism of OBP variability with wind stress curl forced by ENSO using a non-Boussinesq ocean model. Such result is further confirmed by Chambers (2011) using longer-time span GRACE data. An OBP monitoring in the southeastern Pacific was carried out by Fujimoto et al. (2003) for 14 months from 1997 to 1998. It is observed that the local OBP increased in December 1997 in company with the $1997 / 1998$ ENSO.

Although previous studies discovered the active OBP in the South Pacific during high and low frequency timescales (e.g. Boening et al., 2011, 2012; Piecuch et al., 2013; Ponte and Piecuch, 2014), none of the mechanisms have discussed the atmospheric effects on OBP variability in the southeastern Pacific, particularly in light of current efforts to understand what controls regional OBP fluctuations on interannual time scale and to simulate and predict such variability. This is the motivation of this paper. 
The remainder of this paper is organized as follows. Data and methods used in this study are introduced in Sect. 2. Section 3 describes the characteristic and possible mechanism of the interannual variability of OBP in the southeastern Pacific during austral spring and autumn. Finally, Sect. 4 concludes with a discussion.

\section{Data And Method}

Monthly OBP data with a resolution of $1^{\circ} \times 1^{\circ}$ are available for $2003-2016$ from the GRACE Gravimetric Satellite RL06 (release 06) launched by the Center for Space Research (CSR) of the University of Texas. Linear interpolation was performed to reconstruct the values in months to avoid missing values. Atmospheric variables including SLP and surface winds are used from the National Centers for Environmental Prediction-National Center for Atmospheric Research (NCEP-NCAR) atmospheric circulation reanalysis (Kalnay et al., 1996) for the period $2003-2016$ on a $2.5^{\circ} \times 2.5^{\circ}$ grid. Chaudhuri et al. (2013) verified that the zonal winds in different reanalysis products display similar characteristics and they have similar uncertainties when compared against observations. The SST data used in this study are from the National Oceanic and Atmospheric Administration (NOAA) Extended Reconstructed Sea Surface Temperature (ERSST) V5 dataset for the period 2003-2016, which has a horizontal resolution of $2^{\circ} \times 2^{\circ}$ (Huang et al., 2017). The ENSO is indicated by Niño 3.4 index derived from SSTA estimates in the $\left(5^{\circ} \mathrm{N}-5^{\circ} \mathrm{S}, 170^{\circ}-120^{\circ} \mathrm{W}\right)$, downloaded from https://www.esrl.noaa.gov/psd/gcos_wgsp/Timeseries/Nino34/. We calculated the monthly anomalies by subtracting the climatological mean annual cycle (defined by the period of 2003-2012), and the trend has been removed before doing analysis.

Partial correlation is a measure of the linear relationship between two continuous variables whilst controlling for the effect of one or more other continuous variables. The partial correlation is calculated as

$$
R_{12 / 3}=\frac{R_{12}-R_{13} \cdot R_{23}}{\sqrt{\left(1-R_{13}{ }^{2}\right) \cdot\left(1-{R_{23}}^{2}\right)}} \cdots(1),
$$

where $R_{12}, R_{13}$ and $R_{23}$ are the linear correlation coefficients, respectively. $R_{12 / 3}$ is the correlation coefficient between variable 1 and 2 with the variable 3 removed.

The statistical significance of the correlation and regression coefficients are tested with the Student $t$-test, which determines whether two populations express a significant difference between the population means.

\section{Results}

(a) Characteristics of OBP variability in the South Pacific 
The standard deviation map of monthly OBP in the South Pacific from 2003 to 2016 is shown in Fig. $1 \mathrm{a}$. It is obvious that the OBP shows strong variability in the southeastern Pacific. Such result is consistent with Piecuch et al. (2013) and Ponte and Piecuch (2014), which reported that large OBP anomalies variability observed in the Southern Ocean. Then, a simple index that measures the variability of the OBP in the southeastern Pacific (hereafter referred to as the OBP index, OBPI, Fig. 1b) was constructed by the OBP averaged in the $\left(60^{\circ}-45^{\circ} \mathrm{S}, 120^{\circ}-80^{\circ} \mathrm{W}\right.$; black box in Fig. 1a). The largest amplitude of the OBPI is higher than $6 \mathrm{~cm}$ in 2015.

Figure 2 shows the empirical orthogonal function (EOF) analysis of monthly OBP anomalies in the South Pacific $\left(70^{\circ}-30^{\circ} \mathrm{S}, 150^{\circ} \mathrm{E}-60^{\circ} \mathrm{W}\right)$. The leading two EOF modes for the period $2003-2016$ explain $47.7 \%$ and $11.7 \%$ of the total squared covariance, respectively. As shown in Fig. 2a, the positive center of OBP anomalies in the southeastern Pacific $\left(70^{\circ}-45^{\circ} \mathrm{S}, 140^{\circ}-80^{\circ} \mathrm{W}\right)$ is captured by the spatial structure of EOF1, which is similar with the standard deviation map of monthly OBP (Fig. 1a). The principal component (PC) of EOF1 has a close relationship with the OBPI $(R=0.83$, significant at a $99 \%$ confidence level) during the period 2003-2016. Therefore, OBPI can also be used to represent the temporal variation of the EOF1 (i.e. PC1). In contrast, the EOF2 represents a "sea-saw" OBP anomalies in the meridional direction, and the correlation coefficient between the OBPI and PC2 is only 0.03 .

Figure 1c shows the climatological seasonal variation of the OBPI. It is obvious that the OBPI is active during austral spring (ASON) and autumn (MAMJ) but suppressed during austral summer (DJF). Moreover, the amplitudes of PC1 for both the positive and the negative phases are also enhanced from March to November (Fig. 2e), while the PC2 is active during austral summer and winter (Fig. 2f). Thus, the question that will be addressed in this study is-what facilitates energizing the OBP in the southeastern Pacific (Fig. 1a) during austral spring (ASON) and autumn (MAMJ)?

According to the classic theory of Gill and Niiler (1973), low frequency OBP variability is mainly driven by local redistribution of internal mass forced by winds. Regression maps of the OBPI with OBP (contours) and Ekman transports (vectors) during spring (ASON) and autumn (MAMJ) in the South Pacific for the period 2003-2016 are shown in Fig. 3a and 3b, respectively. One can see that OBP is significant positive in the southeastern Pacific consistent with convergence Ekman transports both during spring (ASON) and autumn (MAMJ), indicating the important role of surface winds in OBP variability. Figure $3 \mathrm{c}$ and $3 \mathrm{~d}$ show the regression maps of the OBPI with SLP (contours) and winds at $10 \mathrm{~m}$ (vectors) spring (ASON) and autumn (MAMJ) in the South Pacific for the period 2003-2016, respectively. Positive OBP anomalies in the southeastern Pacific is associated with high pressure and anti-cyclone on the sea level, which is benefit to ocean circulation convergence. Such strong OBP in this region is due to close potential vorticity (PV) contours (caused by ocean topography, white lines in Fig. 1a), which prevent OBP signal propagating westward (Gill and Niller, 1973). However, the low pressures consistent with cyclones over the South Pacific are not coincident during two seasons. There is a significant low pressure in westsouthern Pacific $\left(60^{\circ}-40^{\circ} \mathrm{S}, 180^{\circ}-130^{\circ} \mathrm{W}\right.$; Fig. 3c) during austral autumn (Fig. 3c), but in central-southern Pacific $\left(40^{\circ}-20^{\circ} \mathrm{S}, 160^{\circ}-110^{\circ} \mathrm{W}\right.$; Fig. $\left.3 \mathrm{~d}\right)$ during austral spring (Fig. $\left.3 \mathrm{~d}\right)$. This result suggests that OBP 
variabilities in the South Pacific during different seasons are likely due to different atmosphere variabilities.

(b) mechanisms of $O B P$ variability during austral spring and autumn

To further explore the influence of atmosphere on the OBP in the South Pacific, we compare with the three leading modes of atmospheric variability in the Southern Hemisphere. The canonical Southern Annular Mode (SAM) and Pacific South American (PSA) patterns are usually obtained from EOF analysis of the Southern Hemisphere monthly SLP anomalies (Mo, 2000, Qin et al., 2017). The first three leading EOF modes of the monthly SLP anomalies in the Southern Hemisphere poleward of $20^{\circ} \mathrm{S}$ (after removing the monthly mean global average SLP) for the period 2003-2016 are presented in Fig. 4 (the spatial structures only over the South Pacific are shown). EOF1, EOF2, and EOF3 account for $22.4 \%, 11.8 \%$, and $8.9 \%$ of the SLP variability, respectively. The EOF1 pattern (Fig. $4 \mathrm{a}$ ) is the SAM, which is a dominant mode of atmospheric variability in the Southern Hemisphere. The EOF2 and EOF3 patterns are respectively referred to as PSA1 and PSA2. Moreover, their phases are almost in quadrature, and display a zonal wavenumber-3 structure from the tropical Pacific to Argentina (Fig. 4b and 4c). Correlation coefficients between the OBPI and the time series of the three leading modes (referred to as the SAM index, PSA1 index and PSA2 index, respectively) are listed in Table 1. The OBPI has a high correlation with the PSA2 index during austral spring and autumn $(R=0.74$ and 0.67 , respectively, significant at the $99 \%$ confidence level), which is slightly greater than the correlation between the OBPI and the PSA1 index during austral spring $(R=0.46$, significant at the $90 \%$ confidence level). In contrast, the correlation coefficients between the OBPI and SAM index is below 0.25 (not significant even at the $90 \%$ confidence level). The spatial structures of PSA1 and PSA2 show closed high pressure over the Ocean (Fig. 4b and 4c), which benefits to persistent convergence of Ekman transports. Conversely, the high pressure exist mainly at the south of $60^{\circ} \mathrm{S}$ in SAM (Fig. 4a), leading to ocean circulations toward the Antarctica continent. Thus, the OBP in the southeastern Pacific has the strongest relationship with PSA2, and it is also significantly correlated with PSA1 during austral spring.

Table 1

Correlation coefficients between the OBPI and PCs (obtained by SLP over Southern Hemisphere; Fig. 4) during MAMJ and ASON. * and ** represent the significant at $90 \%$ and $95 \%$ confident level, respectively.

\begin{tabular}{|llll|}
\hline Correlation & the SAM index & the PSA1 index & the PSA2 index \\
\hline MAMJ OBPI & -0.21 & -0.02 & $0.74^{* *}$ \\
\hline ASON OBPI & -0.22 & $0.46^{*}$ & $0.67^{\star *}$ \\
\hline
\end{tabular}

Figure 5 shows partial regressions of the OBPI on OBP anomalies, Ekman transport, SLP and winds at $10 \mathrm{~m}$ in South Pacific during austral spring (ASON) and autumn (MAMJ) with the PSA2 index removed. Compared with Fig. 3 , it is shown that partial regressions of positive OBP anomalies and Ekman 
transports are remarkably reduced in the southeastern Pacific and the triple pattern of SLP becomes indistinct after the PSA2 index removed from the OBPI. Thus, it can be concluded that the PSA2 (the spatial structure of PC3, Fig. 4c) plays an important action role in the OBP variability in the southeastern Pacific. However, the PSA2 only explain approximately $45 \%$ of the OBP variability, and the residual regression of SLP during austral spring (ASON, Fig. 5d) is close to the spatial structure of PSA2 (Fig. 4b), which indicates other factors in affecting the OBP variability in the southeastern Pacific.

Previous studies found that the energy of ENSO can be transmitted from the low latitudes to the mid and high latitudes of the Southern Hemisphere by PSA wave trains, allowing the influence of ENSO to extend from the tropics to the extratropics (e.g. Mo, 2000, Yu et al., 2015). As shown in Fig. 6a, the Niño 3.4 index during austral summer shows highest correlation (significant at the $95 \%$ confidence level) with the MAMJ-averaged PSA2 index (blue line) when ENSO leads the PSA2 around 3 months, but the correlation between the Niño 3.4 index and PSA1 index is extremely low (read line). Although both PSA indices have significant correlation with the Niño 3.4 index during austral spring (Fig. 6b), the correlation coefficient of the Niño 3.4 index with the PSA1 index is higher than that with the PSA2 index. Furthermore, the correlation coefficient between the D(-1)JF-averaged Niño 3.4 index and the MAMJ-averaged OBPI is 0.46, and the correlation coefficient between the Niño 3.4 index and OBPI during austral spring (ASON) is 0.74 , both of which are significant at $95 \%$ confidence level.

Figure 7 show the regression maps of SST anomalies with the MAMJ-averaged and ASON-averaged OBPI in the tropical and South Pacific for the period 2003-2016. The SST anomalies associated with the MAMJ-averaged OBPI are dominated by negative anomalies in the western tropical Pacific and positive anomalies in the eastern tropical Pacific during austral summer (Fig. 7a). Similar result can be seen in Fig. 7d, which represents the regression map of SST anomalies with the OBPI during austral spring (ASON). In contrast, the regression of SST anomalies does not show "ENSO-like" pattern during austral summer (D-1JF) associated with the ASON-averaged OBPI (Fig. 7b) and during austral autumn (MAMJ) associated with the MAMJ-averaged OBPI (Fig. 7c). Therefore, these results verify the influence of ENSO on OBP variability during austral spring (ASON) and autumn (MAMJ) in the southeastern Pacific.

To further illustrate the independent relationship of ENSO and PSAs with OBP variability, partial correlation is carried out. The partial correlation between the PSA indices and OBPI during austral spring (ASON) and autumn (MAMJ) are listed in Table 2 with the Niño 3.4 index removed. Note that the D(-1)JFaveraged Niño 3.4 index is removed during austral autumn (MAMJ). Additionally, the correlation coefficients of the OBPI with PSA1 and PSA2 indices almost unchanged with ENSO removed during austral autumn (MAMJ). It is evident that only the PSA2 index remains significant correlation with the OBPI during austral spring (ASON) and autumn (MAMJ). However, correlation coefficient between the PSA1 index and OBPI declined and non-significant after the Niño 3.4 index removed during austral spring (ASON), indicating that the PSA1 (the spatial structure of PC2, Fig. 4c) links ENSO to the OBP variability in the southeastern Pacific. 
Table 2

is the same as Table 1, but with D(-1)JF ENSO and concurrent ENSO removed.

\begin{tabular}{|llll|}
\hline With D(-1)JF ENSO removed & the SAM index & the PSA1 index & the PSA2 index \\
\hline MAMJ OBPI & -0.09 & 0.09 & $0.66^{\star *}$ \\
\hline ASON OBPI & -0.22 & $0.50^{\star *}$ & $0.69^{\star \star}$ \\
\hline With concurrent ENSO removed & the SAM index & the PSA1 index & the PSA2 index \\
\hline MAMJ OBPI & -0.07 & -0.03 & $0.73^{\star *}$ \\
\hline ASON OBPI & -0.12 & -0.20 & $0.50^{\star *}$ \\
\hline
\end{tabular}

Partial regression maps of the OBPI on OBP anomalies, Ekman transport, SLP and winds at 10m during austral spring (MAMJ) are shown in Fig. 8a and $8 \mathrm{c}$ with the D(-1)JF ENSO removed. Compared with Fig. 3, the OBP and SLP anomalies (especially the positive centers) are weaker in the southeastern Pacific. Similar conclusions are yield out by comparing the OBPI during austral autumn (ASON) with the result that the coincident ENSO removed (Fig. 8b and 8d). Moreover, the partial regressions on OBP anomalies, Ekman transport, SLP and winds are negligible after removing PSA2 and ENSO (not shown). Therefore, it is our conclusion that the energetic OBP variabilities in the southeastern Pacific are dominated by PSA2 and ENSO during austral spring (ASON) and autumn (MAMJ)

\section{(c) $O B P$ variability in PCOM}

To further examine the mechanism of PSA2 and ENSO related processes on OBP variability, the Pressure Coordinate Ocean Model (PCOM) is used in this study. PCOM is a mass conservation (non-Boussinesq approximation) ocean model, which can be used to directly simulate the OBP. See Huang et al. (2001) and Zhang et al. (2014) for more detailed descriptions about the model. In this study, a spin-up run in PCOM with 60 pressure layers and the horizontal resolution of $1^{\circ} \times 1^{\circ}$, was performed for 600 years from a static state under repeating climatological monthly mean atmospheric forcing, including fresh water flux, surface heat flux, surface wind and SLP. To examine the contributions of wind and sea level pressure forcing to the OBP variability, two experiments are carried out from 1990 to 2018 restarting from the spinup run. The control run (Exp.1) is forced by daily atmospheric forcing during 1990-2018. Exp. 2 is the same as the control run, except excluding wind forcing. As shown in Fig. 9a, the pattern of OBP variance in the southeastern Pacific is quite similar to observations (Fig. 1a), especially in $60^{\circ}-45^{\circ} \mathrm{S}, 120^{\circ}-80^{\circ} \mathrm{W}$ (black box in Fig. 1a), which indicates that the PCOM can reproduce interannual variability of OBP quite well. Without wind forcing, the variance of OBP is quite weak, except along the coasts and Mid-Ridges (Fig. 9b), where the non-static response to sea level pressure forcing cannot be neglected. Thus, the control run in PCOM is used for further studies.

The PCOM OBPI is calculated by the PCOM OBP averaged in the $\left(60^{\circ}-45^{\circ} \mathrm{S}, 120^{\circ}-80^{\circ} \mathrm{W}\right.$; black box in Fig. 1a). The correlation coefficient between the monthly observed OBPI (red line, also shown in Fig. 1b) and 
PCOM OBPI (blue line) is 0.66 (significant at $99 \%$ confidence level, Fig. 10a). As shown in Fig. 10b, the OBPI in PCOM also active during austral spring (ASON) and autumn (MAMJ). The EOF1 calculated by PCOM OBP in the South Pacific (Fig. 10c) is also similar with that in GRACE (Fig. 2a), which is captured by positive OBP anomalies in the southeastern Pacific. In addition, the PC1 (Fig. 10d) has high correlation with that in observation ( $R=0.93$, significant at $99 \%$ confidence level).

Regression maps of the PCOM OBPI with OBP anomalies in PCOM, Ekman transports, SLP and winds at $10 \mathrm{~m}$ during austral spring (ASON) and autumn (MAMJ) in the South Pacific for the period 2003-2016 are shown in Fig. 11. The convergence Ekman transports are forced by high pressure and anti-cyclone, leading to positive OBP anomalies in the southeastern Pacific. Such result is the same with observations (Fig. 3). Furthermore, PSA2 has close relationship with the PCOM OBPI (exceed 0.60, listed in Table 3), and the significant correlation decrease slightly after ENSO removed. Therefore, it is confirmed that the interannual OBP variability in the southeastern Pacific is attribute to ENSO and PSA2 during austral spring (ASON) and autumn (MAMJ).

Table 3

Correlation coefficients of the PCOM OBPI with ENSO and PSA2 during MAMJ and ASON. * and ** represent the significant at $90 \%$ and $95 \%$ confident level, respectively.

\begin{tabular}{|llll|}
\hline Correlation & the PSA2 index & Niño 3.4 index & the PSA2 index with ENSO removed \\
\hline MAMJ OBPI & $0.83^{\star *}$ & $0.56^{\star *} \mathrm{D}(-1) \mathrm{JF}$ & $0.72^{\star *}$ \\
\hline ASON OBPI & $0.60^{\star *}$ & $0.82^{\star *}$ ASON & $0.45^{\star}$ \\
\hline
\end{tabular}

\section{Conclusion And Discussion}

In this study, we examined the interannual characteristic of OBP in the South Pacific during austral spring (ASON) and autumn (MAMJ). We conclude that the variability of OBP in the southeastern Pacific is mainly controlled by Ekman transport driven by wind stress. During the positive OBP anomalies in the southeastern Pacific, a strong and persistent anticyclone is forced by wavenumber-3 structure of atmospheric circulation anomalies over the South Pacific (Fig. 12), and vice versa. Such atmospheric circulation anomalies are similar to a PSA2-type wave train over the South Pacific during austral spring (ASON) and autumn (MAMJ). Additionally, ENSO also plays an important role in the OBP variability in the southeastern Pacific. PSA wave trains and atmospheric circulation variability link the influence of ENSO to extratropics. The OBP anomalies during austral spring are influenced by coincide ENSO and the OBP anomalies during austral autumn are affected by austral summer ENSO.

The findings of this study emphasize the role played by PSA2 and ENSO in OBP variability in the southeastern Pacific. Atmospheric circulation anomalies can explain 64\% (PSA2 44\%,ENSO 20\%) of OBP variability during austral spring (ASON), and 80\% (PSA2 25\% ENSO 55\%) of OBP variability during austral autumn (MAMJ). This result helps to understand the reason for controlling regional OBP 
fluctuations on interannual time scale, and to simulate and predict OBP variability in the southeastern Pacific.

However, the GRACE data processes have only 14 years, which are too short to give a long-term perspective of the correlation between the interannual OBP variability and the ENSO events. It is evident that PCOM, a mass conservation model, can reproduce interannual OBP variability quite well in the South Pacific. Therefore, PCOM simulations provide not only a long-term solution for a better understanding of the OBP variability mechanisms but also predicting sea level change in the future.

\section{Declarations}

\section{Acknowledgement}

This research was supported by the National Key R\&D Program of China (2018YFA0605702), Natural Science Foundation of China (Grant nos. 41522601, 41876002, 41876224). All reanalysis products and observation data for this paper are properly cited and referred to in the reference list. ERSST are available at https://psl.noaa.gov/data/gridded/data.noaa.ersst.v5.html. NCEP-NCAR reanalysis are available at https://www.esrl.noaa.gov/psd/data/gridded/data.ncep.reanalysis.html. GRACE OBP products were made available by the NASA MEASURES Program, and are available at http://GRACE.jpl.nasa.gov.

\section{References}

1. Bjerknes J (1969) ATMOSPHERIC TELECONNECTIONS FROM THE EQUATORIAL PACIFIC1. Mon Weather Rev 97. https://doi.org/10.1175/1520-0493(1969)0972.3.CO;2

2. Boening C, Lee T, Zlotnicki V (2011) A record-high ocean bottom pressure in the South Pacific observed by GRACE. Geophys Res Lett 38. https://doi.org/10.1029/2010gl046013

3. Boening C, Willis JK, Landerer FW, Nerem RS, Fasullo J (2012) The 2011 La Niña: So strong, the oceans fell. Geophys Res Lett 39. https://doi.org/10.1029/2012gl053055

4. Cabanes C, Huck T, Alain CDV (2006) Contributions of wind forcing and surface heating to interannual sea level variations in the Atlantic Ocean. J Phys Oceanogr 36:1739-1750. https://doi.org/10.1175/JP02935.1

5. Cazenave A (2004) Present-day sea level change: Observations and causes. Rev Geophys 42. https://doi.org/10.1029/2003rg000139

6. Cazenave A, Henry O, Munier S et al (2012) Estimating ENSO Influence on the Global Mean Sea Level, 1993-2010. Mar Geod 35:82-97. https://doi.org/10.1080/01490419.2012.718209

7. Chambers DP (2006a) Evaluation of new GRACE time-variable gravity data over the ocean. Geophys Res Lett 33. https://doi.org/10.1029/2006gl027296

8. Chambers DP (2006b) Observing seasonal steric sea level variations with GRACE and satellite altimetry. J Geophys Res 111. https://doi.org/10.1029/2005jc002914 
9. Chambers DP (2011) ENSO-correlated fluctuations in ocean bottom pressure and wind-stress curl in the North Pacific. Ocean Sci 7:685-692. https://doi.org/10.5194/os-7-685-2011

10. Chambers DP, Cazenave A, Champollion N et al (2017) Evaluation of the Global Mean Sea Level Budget between 1993 and 2014. Surv Geophys 38:309-327. https://doi.org/10.1007/s10712-0169381-3

11. Chambers DP, Wahr J, Nerem RS (2004) Preliminary observations of global ocean mass variations with GRACE. Geophys Res Lett 31. https://doi.org/10.1029/2004gl020461

12. Chaudhuri AH, Ponte RM, Forget G, Heimbach $P$ (2013). A comparison of atmospheric reanalysis surface products over the ocean and implications for uncertainties in air-sea boundary forcing. $J$ Clim 26: 153-170. https://doi.org/10.1175/JCLI-D-12-00090.1

13. Cheng X, Li L, Du Y, Wang J, Huang R (2013) Mass-induced sea level change in the northwestern North Pacific and its contribution to total sea level change. Geophys Res Lett 40:3975-3980. https://doi.org/10.1002/grl.50748

14. Fujimoto $\mathrm{H}$ (2003) Ocean bottom pressure variations in the southeastern Pacific following the 199798 El Niño event. Geophys Res Lett 30. https://doi.org/10.1029/2002gl016677

15. Gill AE, Niller PP (1973) The theory of the seasonal variability in the ocean. Deep-Sea Res Oceanogr Abstr 20:141-177. https://doi.org/10.1016/0011-7471(73)90049-1

16. Horel JD, Wallace JM (1981) Planetary-Scale Atmospheric Phenomena Associated with the Southern Oscillation. Mon Weather Rev 109:813-829. https://doi.org/10.1175/15200493(1981)109<0813:PSAPAW>2.0.C0;2

17. Huang B, Thorne PW, Banzon VF, Boyer T, Zhang HM (2017) Extended Reconstructed Sea Surface Temperature, Version 5 (ERSSTv5): Upgrades, Validations, and Intercomparisons. J Clim 30. https://doi.org/10.1175/JCLI-D-16-0836.1

18. Huang $R$, Jin $X$ (2002) Sea surface elevation and bottom pressure anomalies due to thermohaline forcing. J Phys Oceanogr 32:2131-2150. https://doi.org/10.1175/15200485(2002)032<2131:SSEABP>2.0.CO;2

19. Huang R, Jin X, Zhang X (2001) An Oceanic General Circulation Model in Pressure Coordinates. Adv Atmos Sci 18:1-22. https://doi.org/10.1007/s00376-001-0001-9

20. Johnson GC, Chambers DP (2013) Ocean bottom pressure seasonal cycles and decadal trends from GRACE Release-05: Ocean circulation implications. J Geophys Res: Oceans 118:4228-4240. https://doi.org/10.1002/jgrc.20307

21. Kalnay E, Kanamitsu M, Kistler R et al (1996) The NCEP/NCAR 40-year reanalysis project. Bull Amer Meteorol Soc 77:437-471. https://doi.org/10.1175/1520-0477(1996)077<0437:TNYRP>2.0.C0;2

22. Makowski JK, Chambers DP, Bonin JA (2015) Using ocean bottom pressure from the gravity recovery and climate experiment (GRACE) to estimate transport variability in the southern Indian Ocean. $J$ Geophys Res: Oceans 120:4245-4259. https://doi.org/10.1002/2014jc010575

23. Mo, Kingtse C (2000) Relationships between Low-Frequency Variability in the Southern Hemisphere and Sea Surface Temperature Anomalies. J Clim 13:3599-3610. https://doi.org/10.1175/1520- 
0442(2000)0132.0.CO;2

24. Piecuch CG, Quinn KJ, Ponte RM (2013) Satellite-derived interannual ocean bottom pressure variability and its relation to sea level. Geophys Res Lett 40:3106-3110. https://doi.org/10.1002/grl.50549

25. Ponte RM (1999) A preliminary model study of the large-scale seasonal cycle in bottom pressure over the global ocean. J Geophys Res: Oceans 104:1289-1300. https://doi.org/10.1029/1998jc900028

26. Ponte RM, Piecuch CG (2014) Interannual Bottom Pressure Signals in the Australian-Antarctic and Bellingshausen Basins. J Phys Oceanogr 44:1456-1465. https://doi.org/10.1175/jpo-d-13-0223.1

27. Qin J, Ding R, Wu Z, Li J, Zhao S (2017) Relationships between the extratropical ENSO precursor and leading modes of atmospheric variability in the Southern Hemisphere. Adv Atmos Sci 34:360-370. https://doi.org/10.1007/s00376-016-6016-z

28. Quinn KJ, Ponte RM (2012) High frequency barotropic ocean variability observed by GRACE and satellite altimetry. Geophys Res Lett 39. https://doi.org/10.1029/2012gl051301

29. Ren D, Leslie LM, Lynch MJ (2013) Verification of model simulated mass balance, flow fields and tabular calving events of the Antarctic ice sheet against remotely sensed observations. Clim Dyn 40:2617-2636. https://doi.org/10.1007/s00382-012-1464-3

30. Simpson MJR, Breili K, Kierulf HP (2014) Estimates of twenty-first century sea-level changes for Norway. Clim Dyn 42:1405-1424. https://doi.org/10.1007/s00382-013-1900-z

31. Song YT, Zlotnicki V (2008) Subpolar ocean bottom pressure oscillation and its links to the tropical ENSO. Int J Remote Sens 29:6091-6107. https://doi.org/10.1080/01431160802175538

32. Srinivasu U, Ravichandran M, Han W et al (2017) Causes for the reversal of North Indian Ocean decadal sea level trend in recent two decades. Clim Dyn 49, 3887-3904 (2017). https://doi.org/10.1007/s00382-017-3551-y

33. Stepanov VN, Hughes CW (2006) Propagation of signals in basin-scale ocean bottom pressure from a barotropic model. J Geophys Res 111. https://doi.org/10.1029/2005jc003450

34. Storto A, Masina S, Balmaseda M et al (2015) Steric sea level variability (1993-2010) in an ensemble of ocean reanalyses and objective analyses. Clim Dyn 49:709-729. https://doi.org/10.1007/s00382-015-2554-9

35. Tapley BD, Bettadpur S, Ries JC, Thompson PF, Watkins MM (2004) GRACE measurements of mass variability in the Earth system. Science 305:503-505. https://doi.org/10.1126/science.1099192

36. Velicogna I (2009) Increasing rates of ice mass loss from the Greenland and Antarctic ice sheets revealed by GRACE. Geophys Res Lett 36. https://doi.org/10.1029/2009gl040222

37. Volkov DL, Landerer FW (2015) Internal and external forcing of sea level variability in the Black Sea. Clim Dyn 45:2633-2646. https://doi.org/10.1007/s00382-015-2498-0

38. Willis JK, Chambers DP, Nerem RS (2008) Assessing the globally averaged sea level budget on seasonal to interannual timescales. J Geophys Res 113. https://doi.org/10.1029/2007jc004517 
39. Yu J-Y, Paek H, Saltzman ES, Lee T (2015) The Early 1990s Change in ENSO-PSA-SAM Relationships and Its Impact on Southern Hemisphere Climate. J Clim 28:9393-9408. https://doi.org/10.1175/jcli-d-15-0335.1

40. Zhang Y, Lin Y, Huang R (2014) A climatic dataset of ocean vertical turbulent mixing coefficient based on real energy sources. Sci China: Earth Sci 57:2435-2446. https://doi.org/10.1007/s11430014-4904-6

41. Zlotnicki V, Wahr J, Fukumori I, Song YT (2007) Antarctic Circumpolar Current Transport Variability during 2003-05 from GRACE. J Phys Oceanogr 37:230-244. https://doi.org/10.1175/jpo3009.1

\section{Figures}

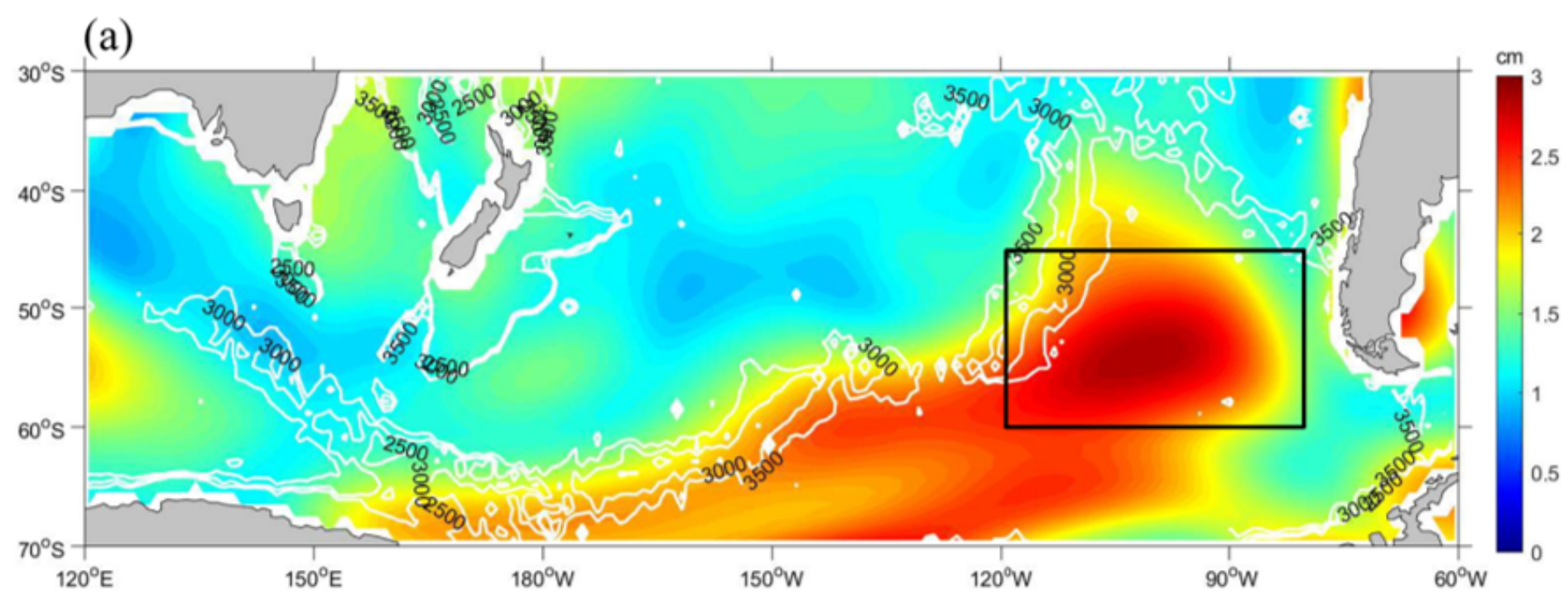

(b)

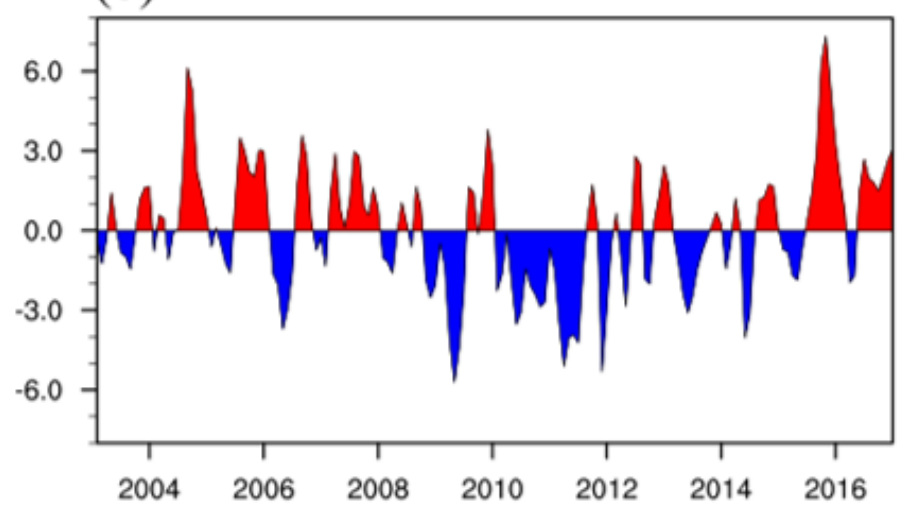

(c)

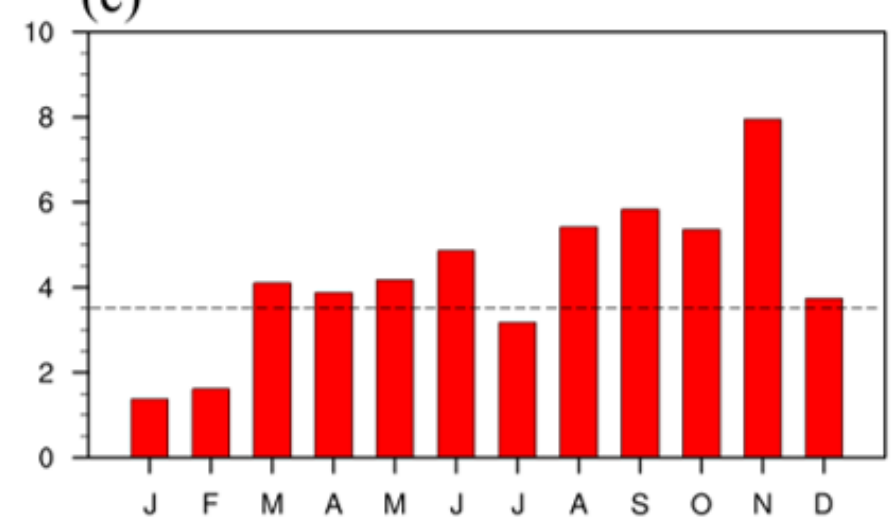

\section{Figure 1}

(a) Standard deviation map of ocean bottom pressure in the South Pacific from 2003 to 2016 . The solid white lines represent the topography between 2500 and $3500 \mathrm{~m}$. (b) The ocean bottom pressure index averaged in the east-south Pacific (black box; $60^{\circ} \otimes 45^{\circ} \mathrm{S}, 120^{\circ} \otimes 80^{\circ} \mathrm{W}$, unit: $\mathrm{cm}$ ). (c) The climatological seasonal variation of OBPI, which is the monthly index from 2003 to 2016 (unit: cm2). 
(a) EOF 1

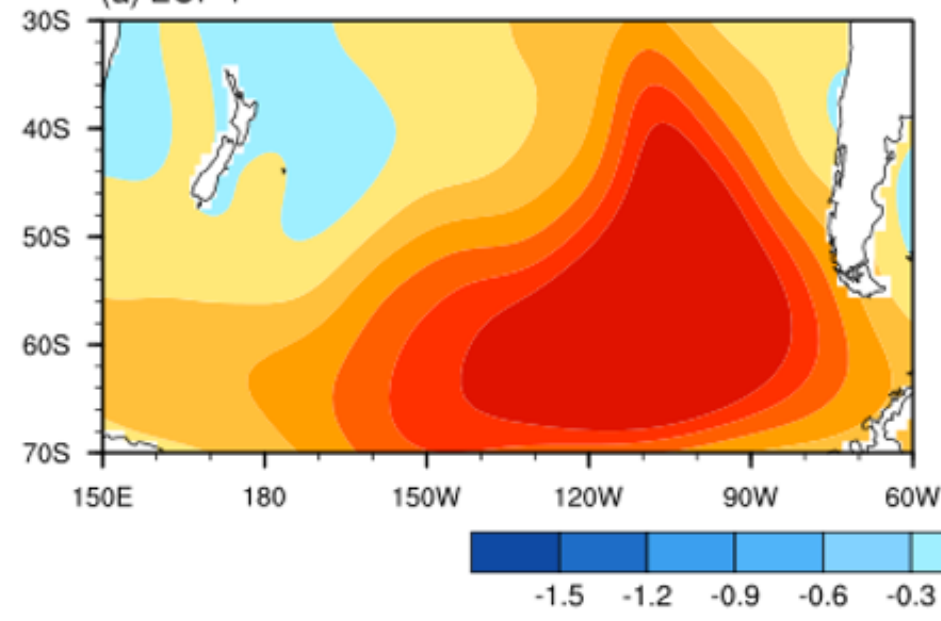

(c) PC 1

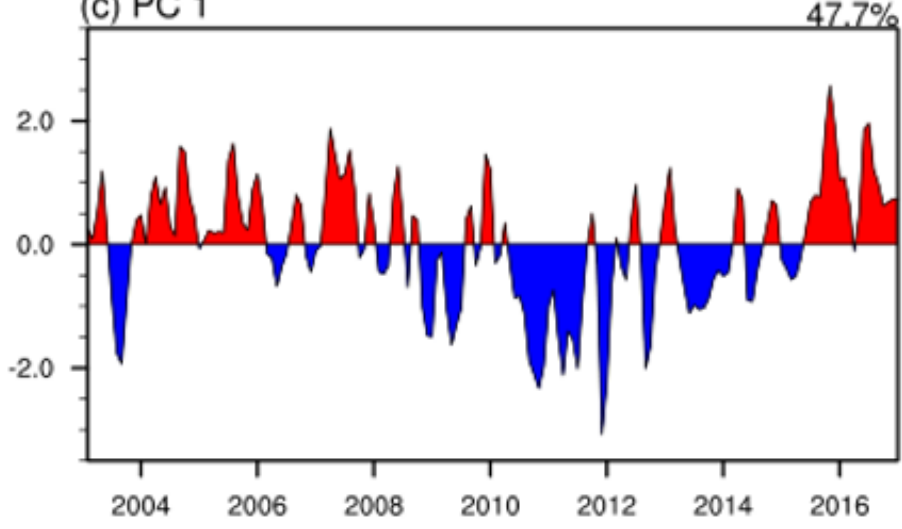

(e)

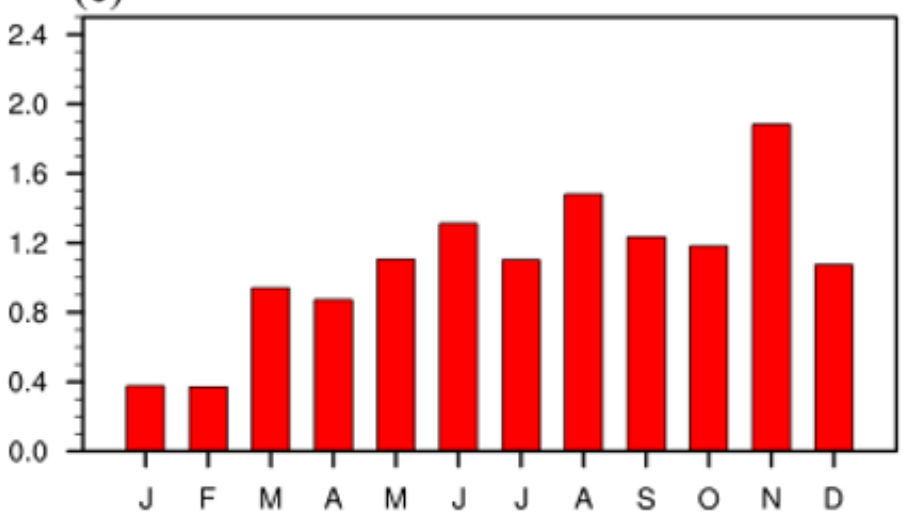

(b) EOF 2

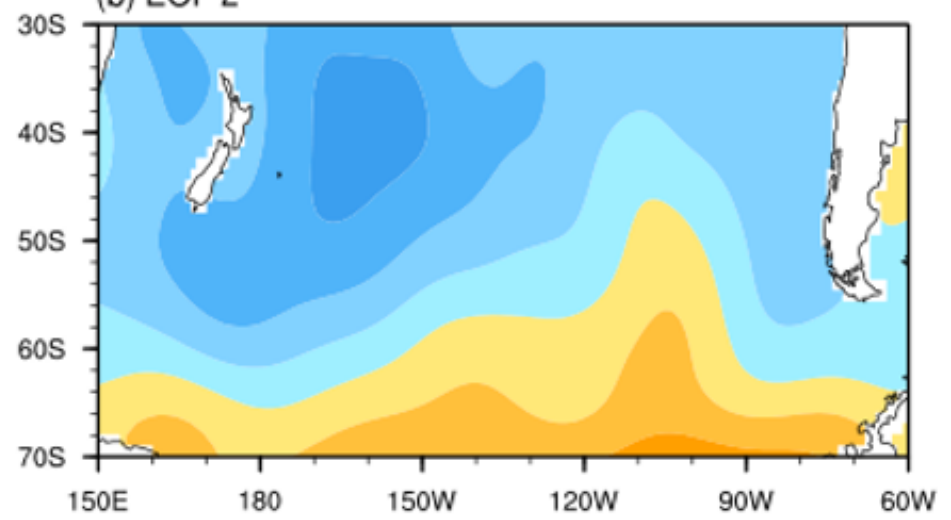

$\begin{array}{llllll}150 \mathrm{E} & 180 & 150 \mathrm{~W} & 120 \mathrm{~W} & 90 \mathrm{~W} & 60 \mathrm{~W}\end{array}$

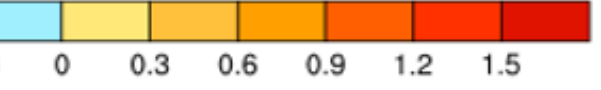

(d) PC 2

$11.7 \%$

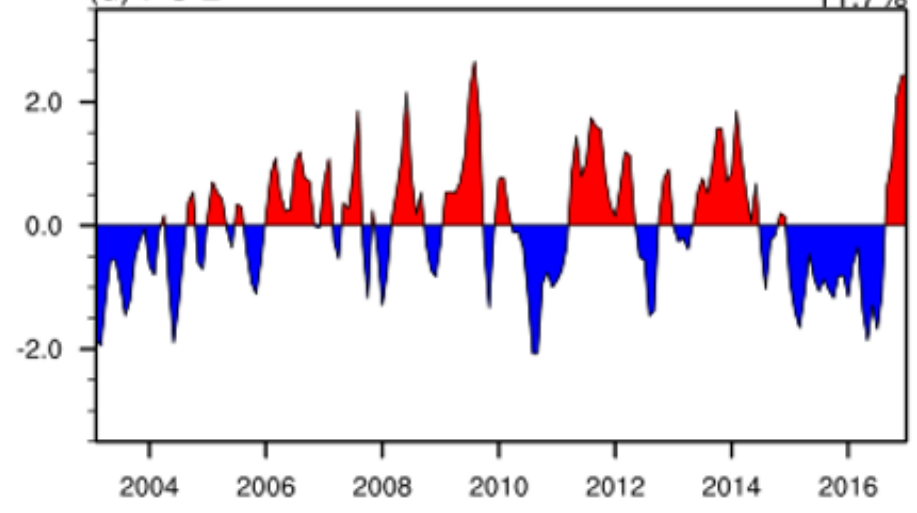

(f)

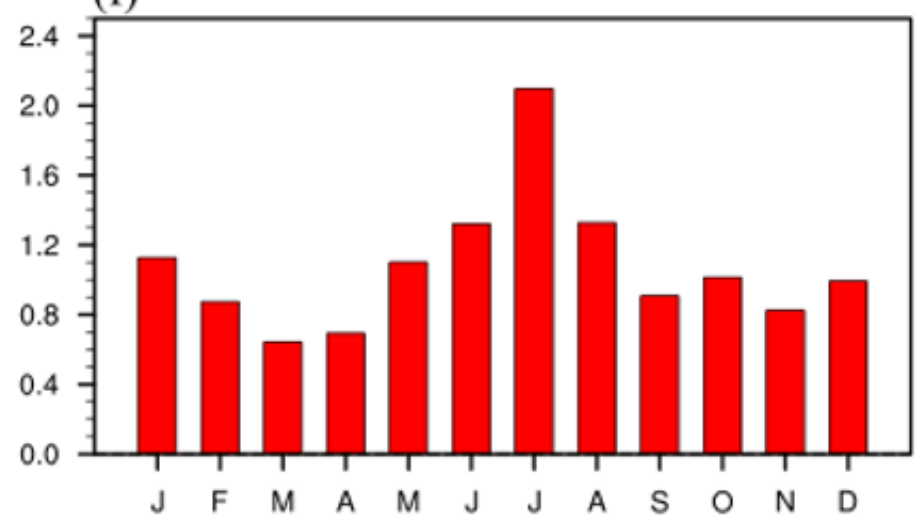

Figure 2

Spatial patterns of (a) EOF1 and (b) EOF2 of the monthly ocean bottom pressure in the South Pacific $\left(70^{\circ} \otimes 30^{\circ} \mathrm{S}, 150^{\circ} \mathrm{E} \otimes 60^{\circ} \mathrm{W}\right.$ ) for the period $2003-2016$ (after removing the monthly mean global average ocean bottom pressure anomalies). (c) and (d) are time series of PCs. (e) and (f) are climatological seasonal variation of PCs. 
(a) MAMJ

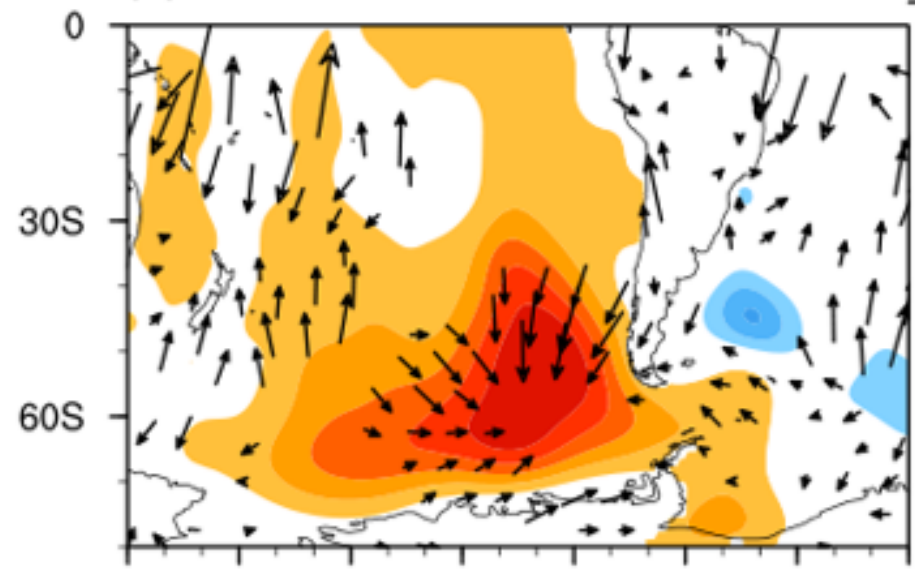

150E 180 150W 120W 90W 60W 30W 0 $\stackrel{0.1}{\longrightarrow}$

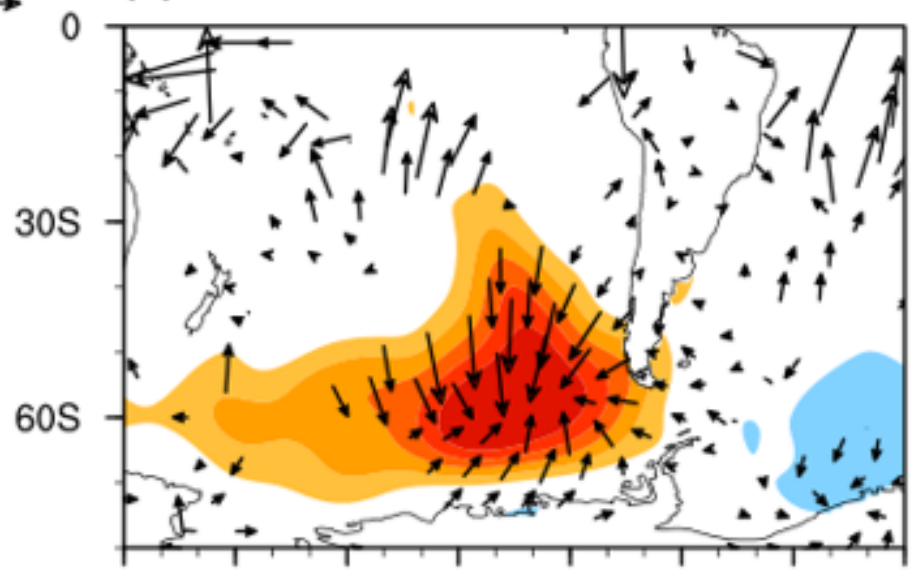

$150 \mathrm{E} 180$ 150W 120W 90W 60W 30W 0

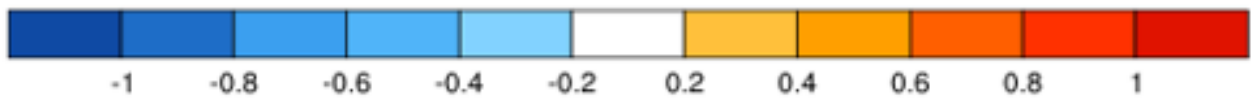

(c) MAMJ

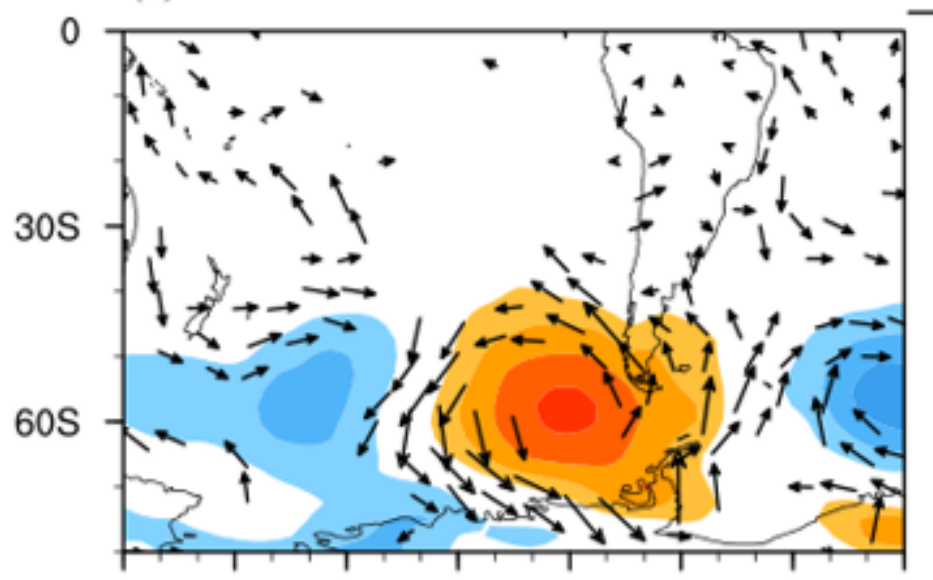

150E 180 150W 120W 90W 60W 30W 0 (d) ASON

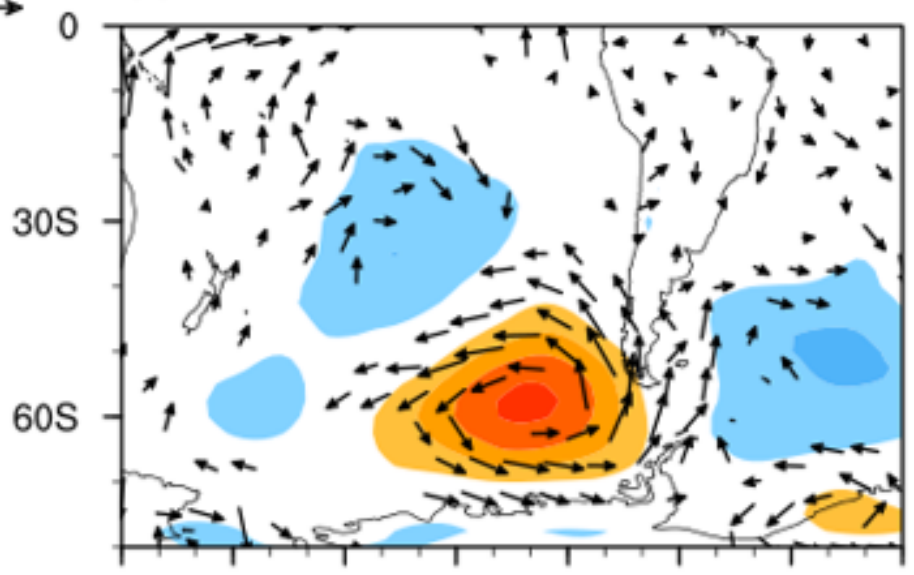

$150 \mathrm{E} 180$ 150W 120W 90W 60W 30W 0

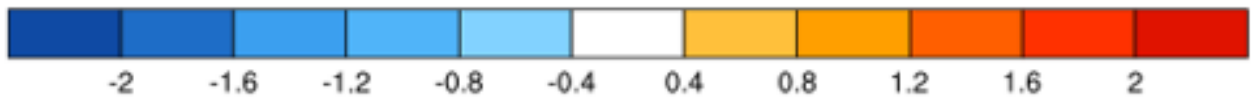

Figure 3

Regression maps of the (a) MAMJ-averaged and (b) ASON-averaged OBPI with the ocean bottom pressure (contours; $\mathrm{cm}$ ) and Ekman transports (vectors; m3/s) in the South Pacific for the period 20032016. Only anomalies which are significant at $95 \%$ significance level are shown. (c) and (d) are the same as (a) and (b), but for sea level pressure (contours; $\mathrm{hPa}$ ) and $10 \mathrm{~m}$ winds (vectors; $\mathrm{m} / \mathrm{s}$ ). 
(a) EOF 1

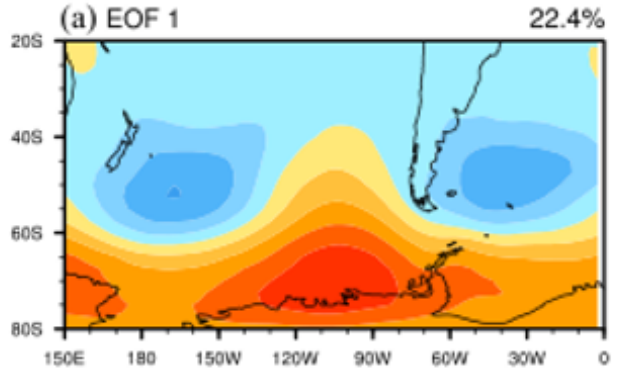

(b) EOF 2
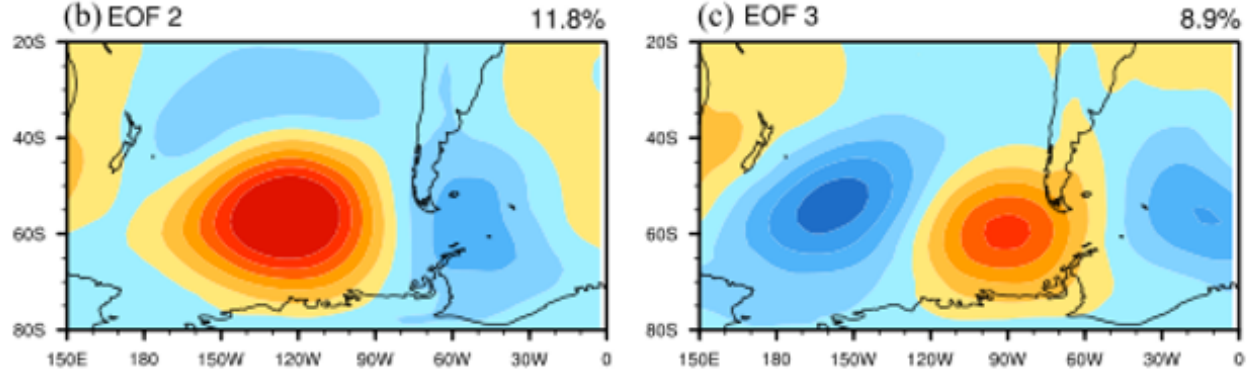

$$
\begin{array}{llllllllllll}
-3 & -2.4 & -1.8 & -1.2 & -0.6 & 0 & 0.6 & 1.2 & 1.8 & 2.4 & 3
\end{array}
$$
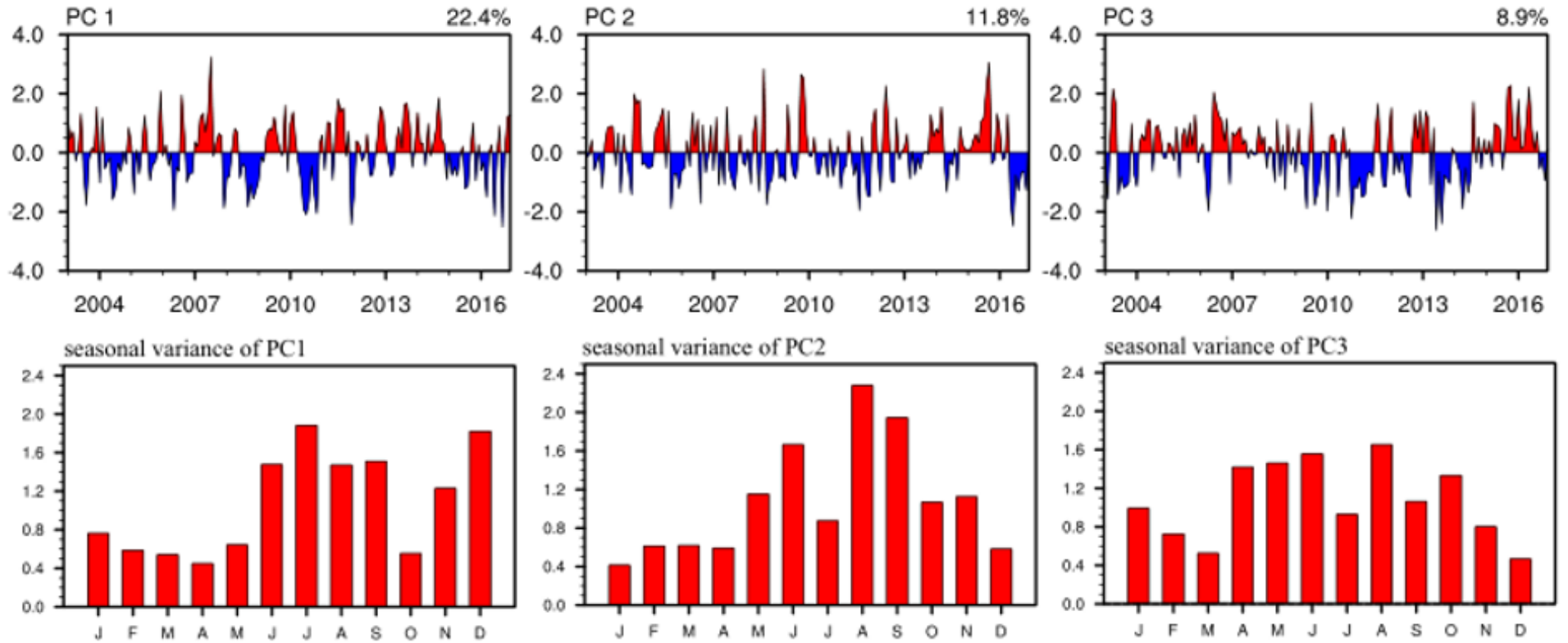

Figure 4

(Top) Spatial patterns of (a) EOF1, (b) EOF2, and (c) EOF3 of the monthly sea level pressure over the Southern Hemisphere poleward of $20^{\circ} \mathrm{S}$ for the period 2003-2016 (after removing the monthly mean global average sea level pressure anomalies). Results only over the South Pacific are shown. (Middle) Time series and (Bottom) climatological seasonal variation of PCs. 
(a) MAMJ

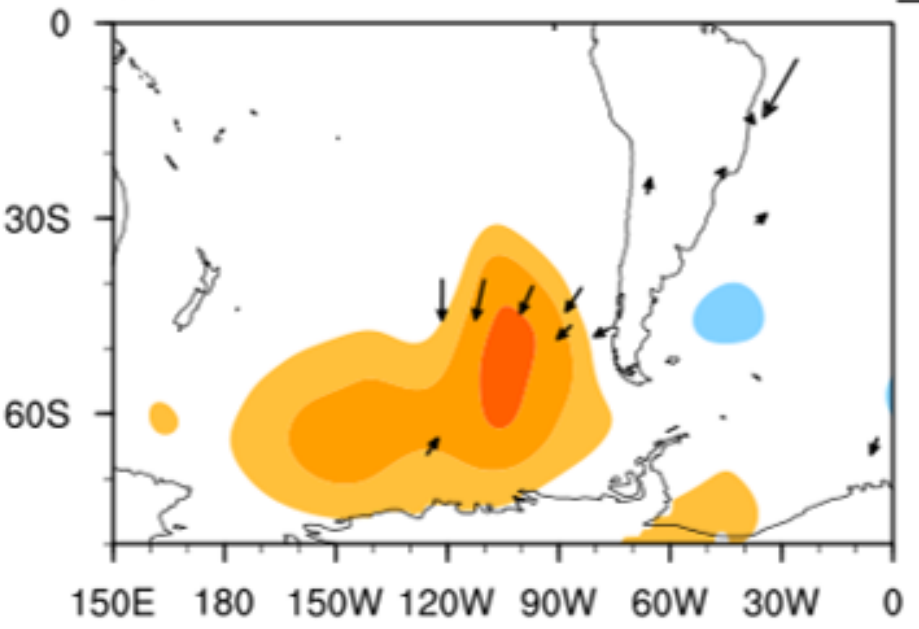

$\stackrel{0.1}{\longrightarrow}$ (b) ASON

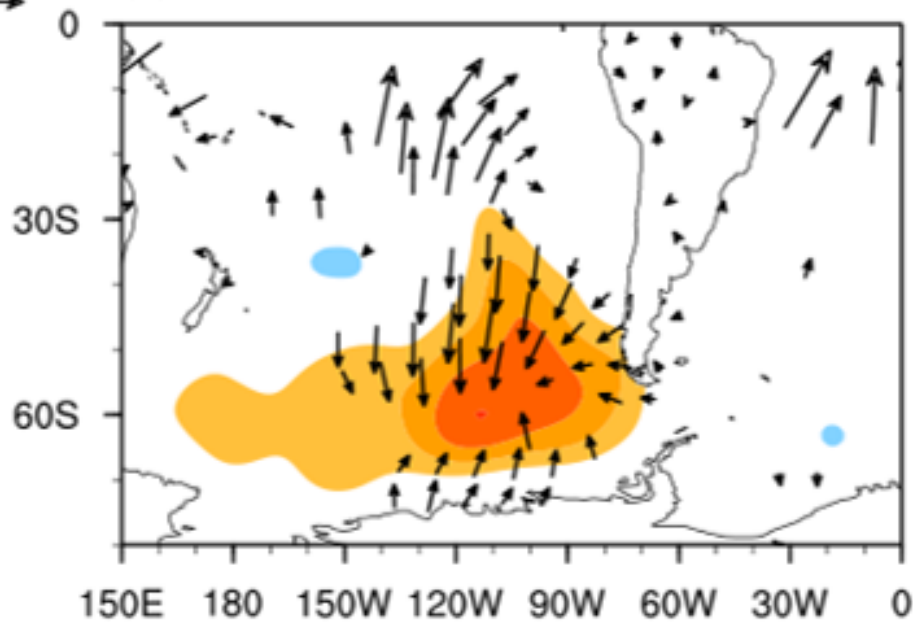

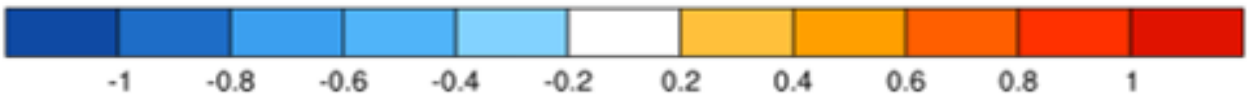

(c) MAMJ

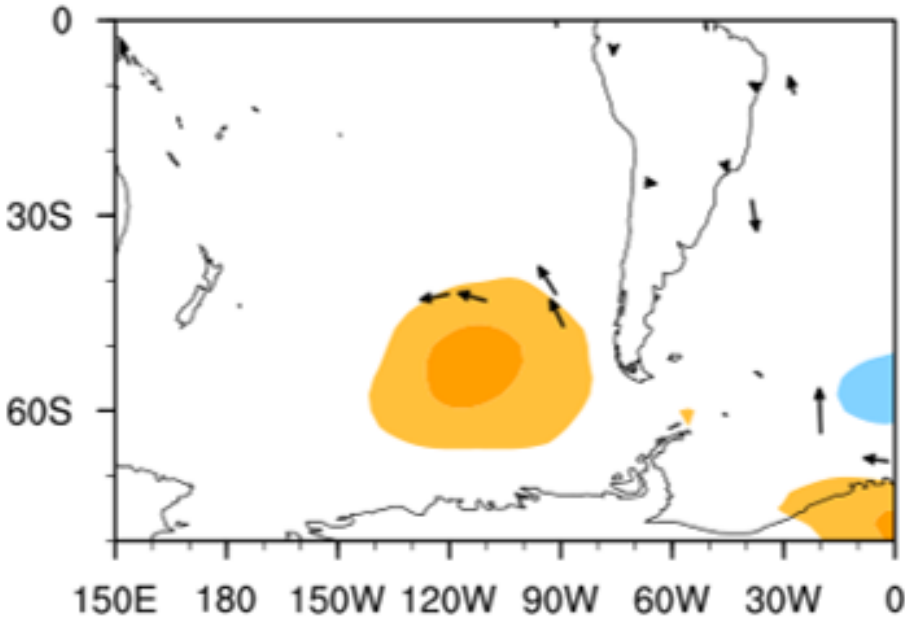

(d) ASON

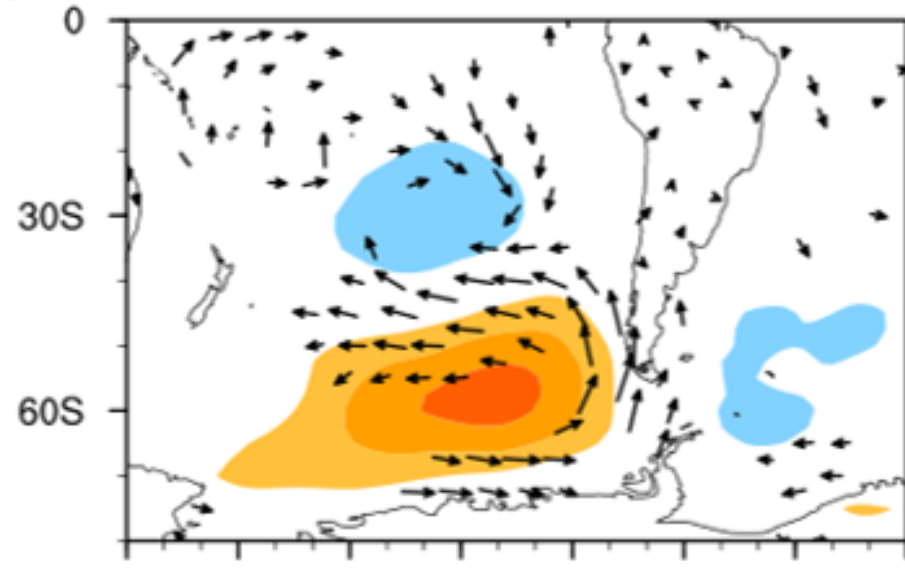

150E 180 150W 120W 90W 60W 30W 0

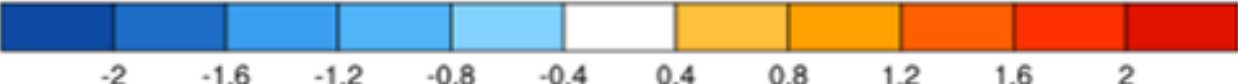

Figure 5

is the same as Fig. 3, but with PSA2 removed. 
(a) lead correlation with MAMJ PCs

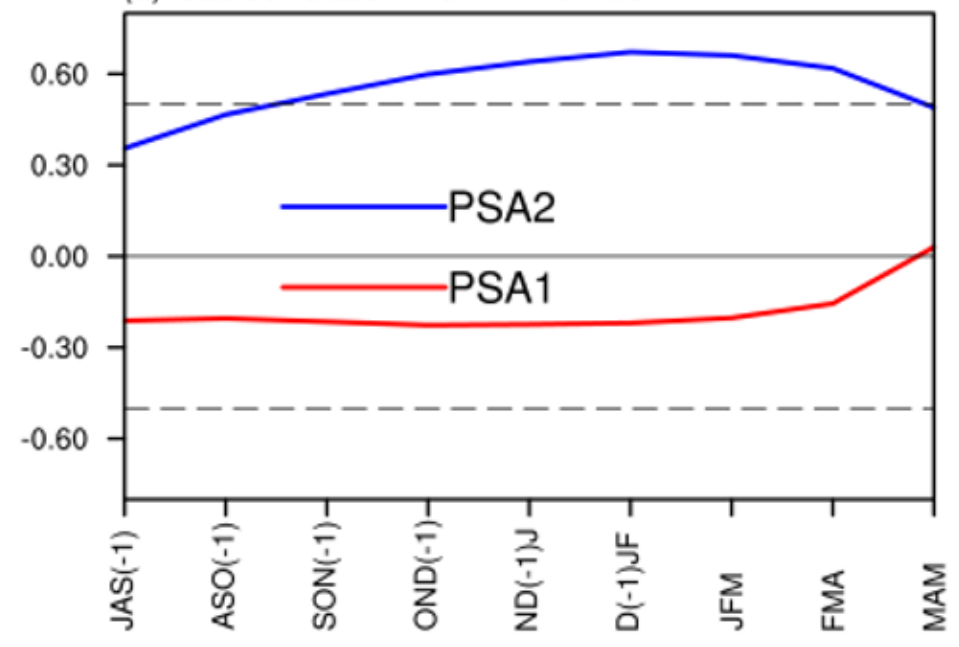

(b) lead correlation with ASON PCs

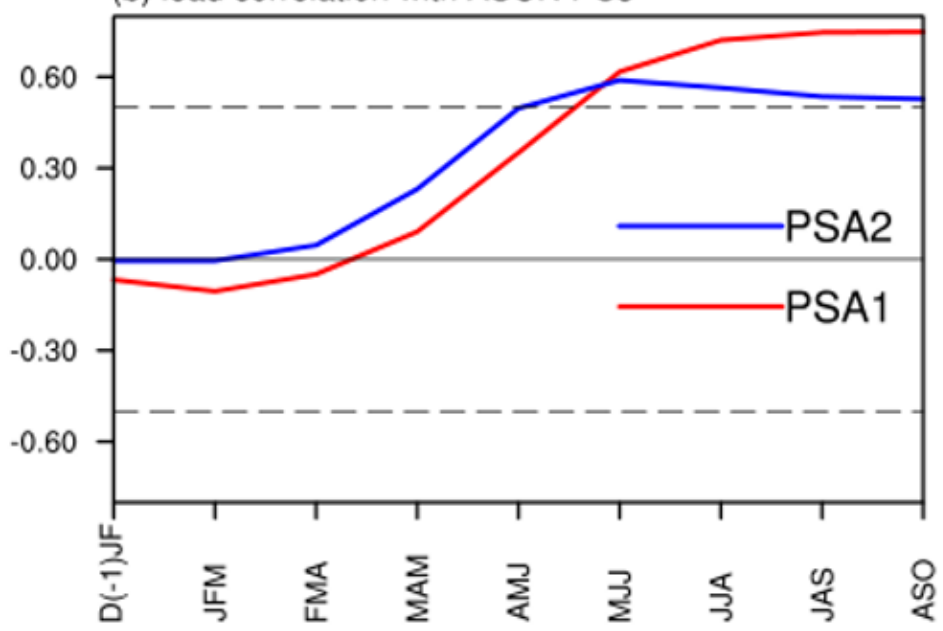

\section{Figure 6}

Lead correlation coefficients of (a) the MAMJ-averaged and (b) the ASON-averaged PSA1 (red line) and PSA2 (blue line) index with the 3 month averaged Niño 3.4 index. The horizontal dashed line shows the $95 \%$ significance level. 
(a) D(-1)JF SST \& MAMJ OBP
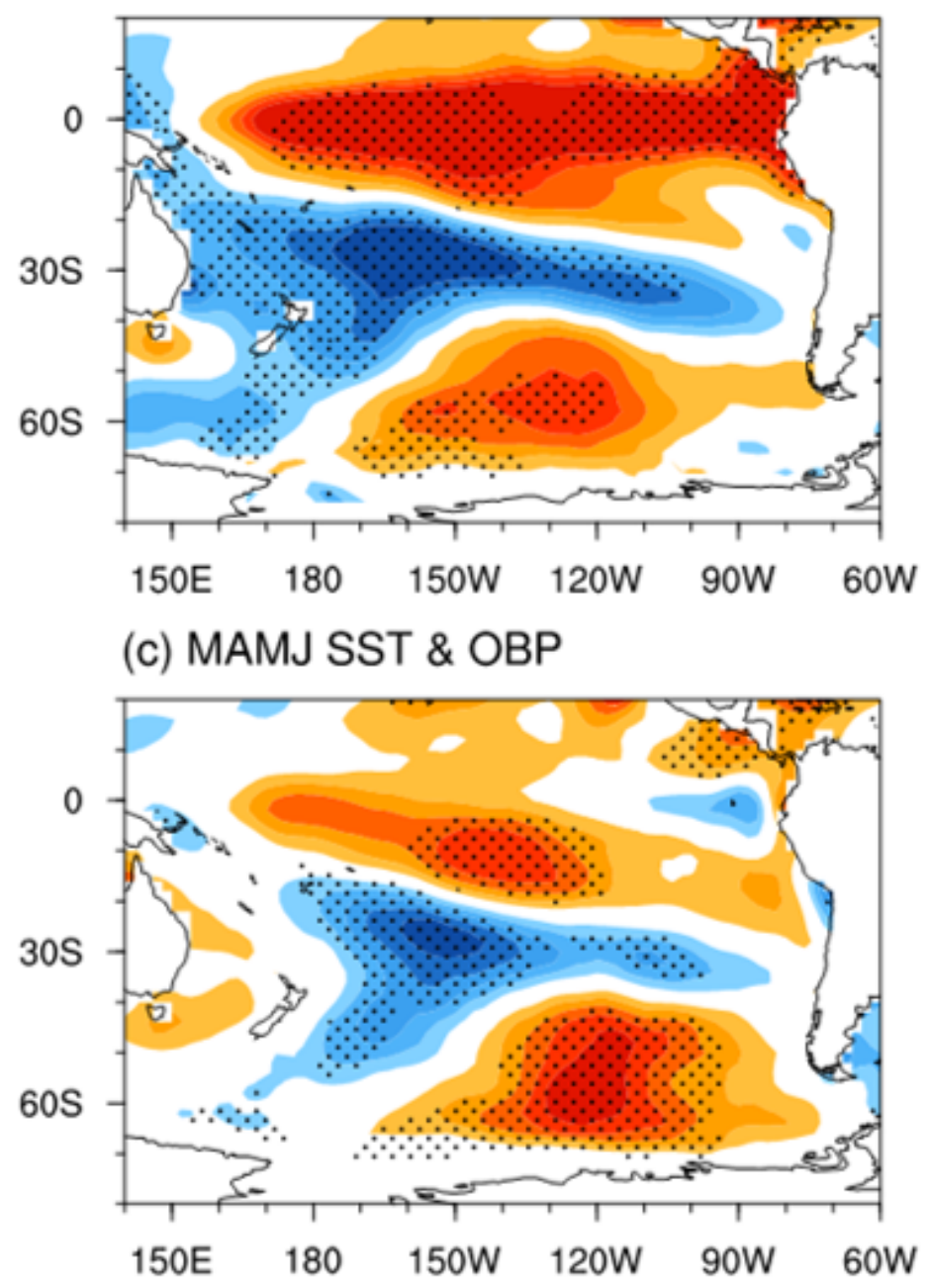

(b) D(-1)JF SST \& ASON OBP
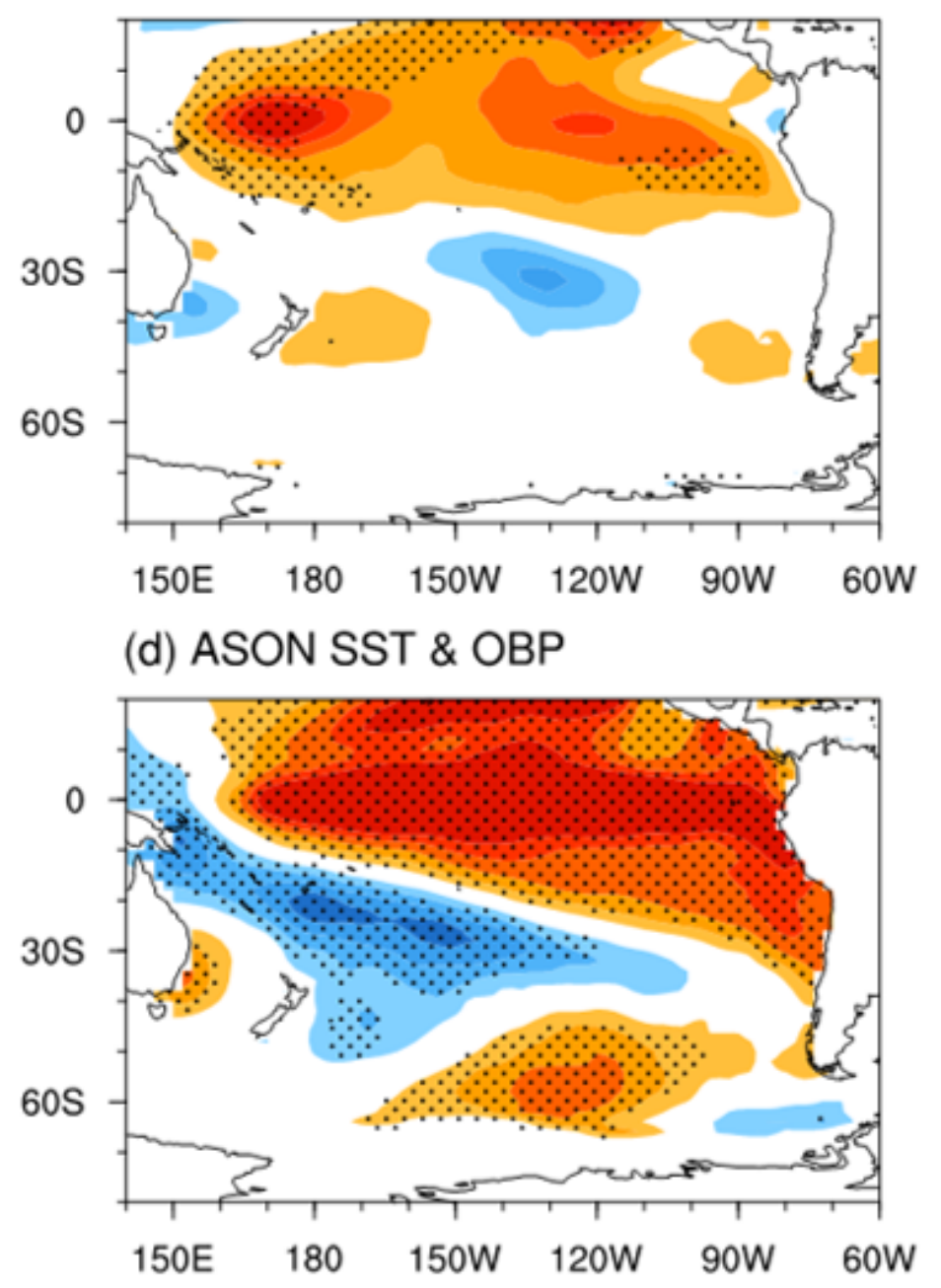

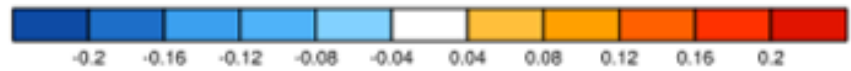

Figure 7

Regression maps of the D(-1) JF-averaged SST anomalies $\left({ }^{\circ} \mathrm{C}\right)$ with the (a) MAMJ-averaged and (b) ASON-averaged OBPI in the tropical and South Pacific for the period 2003-2016. Significant SST anomalies at a 95\% confidence level are stippled. (c) and (d) are the same as (a) and (b), but for the SST anomalies $\left({ }^{\circ} \mathrm{C}\right)$ at the same time. 
(a) MAMJ

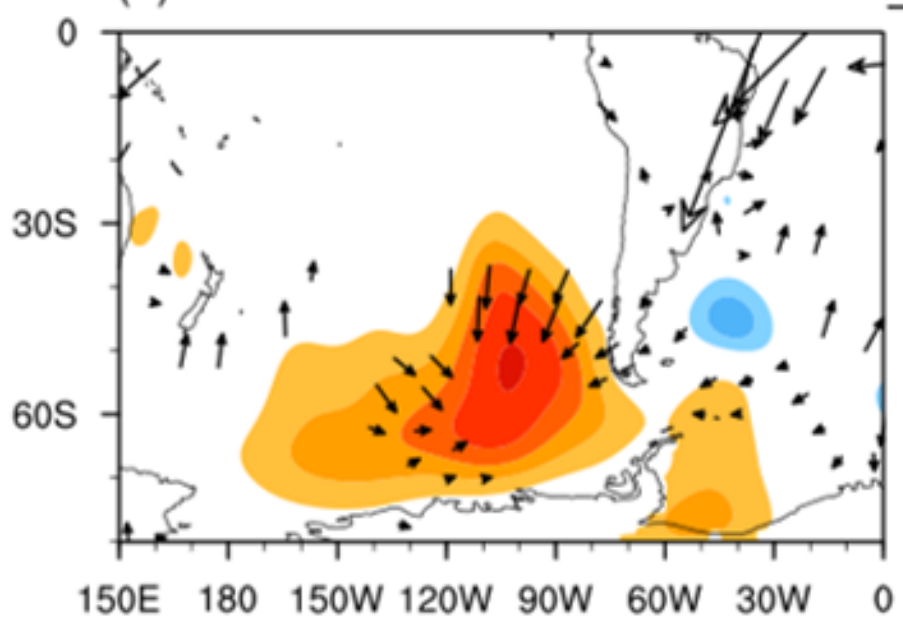

$\underline{0.1}$

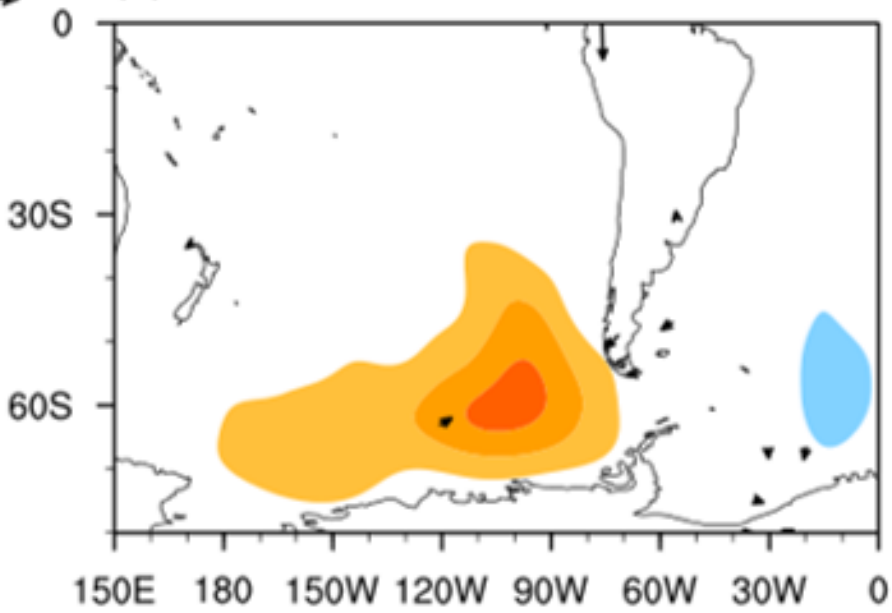

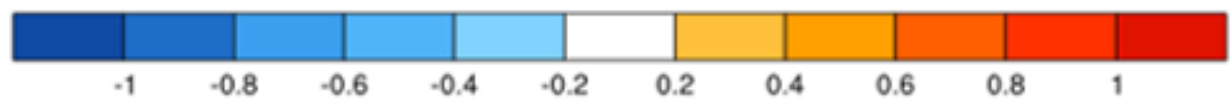

(c) MAMJ

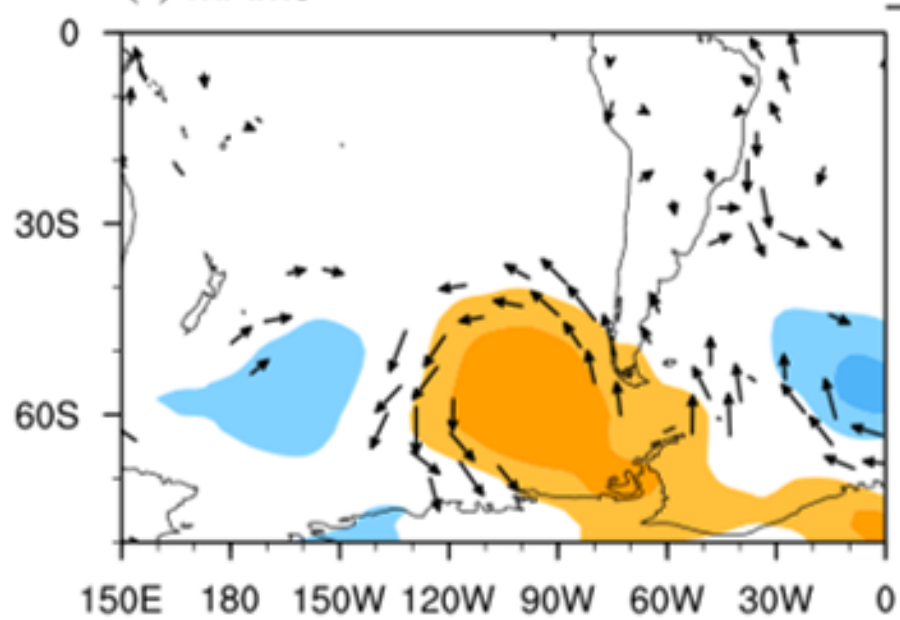

(d) ASON

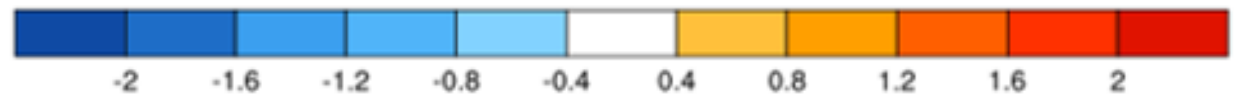

Figure 8

(a) and (c) are the same as Fig. 3 (a) and (c), but with D(-1)JF ENSO removed. (b) and (d) are the same as Fig. 3 (b) and (d), but with concurrent ENSO removed. 


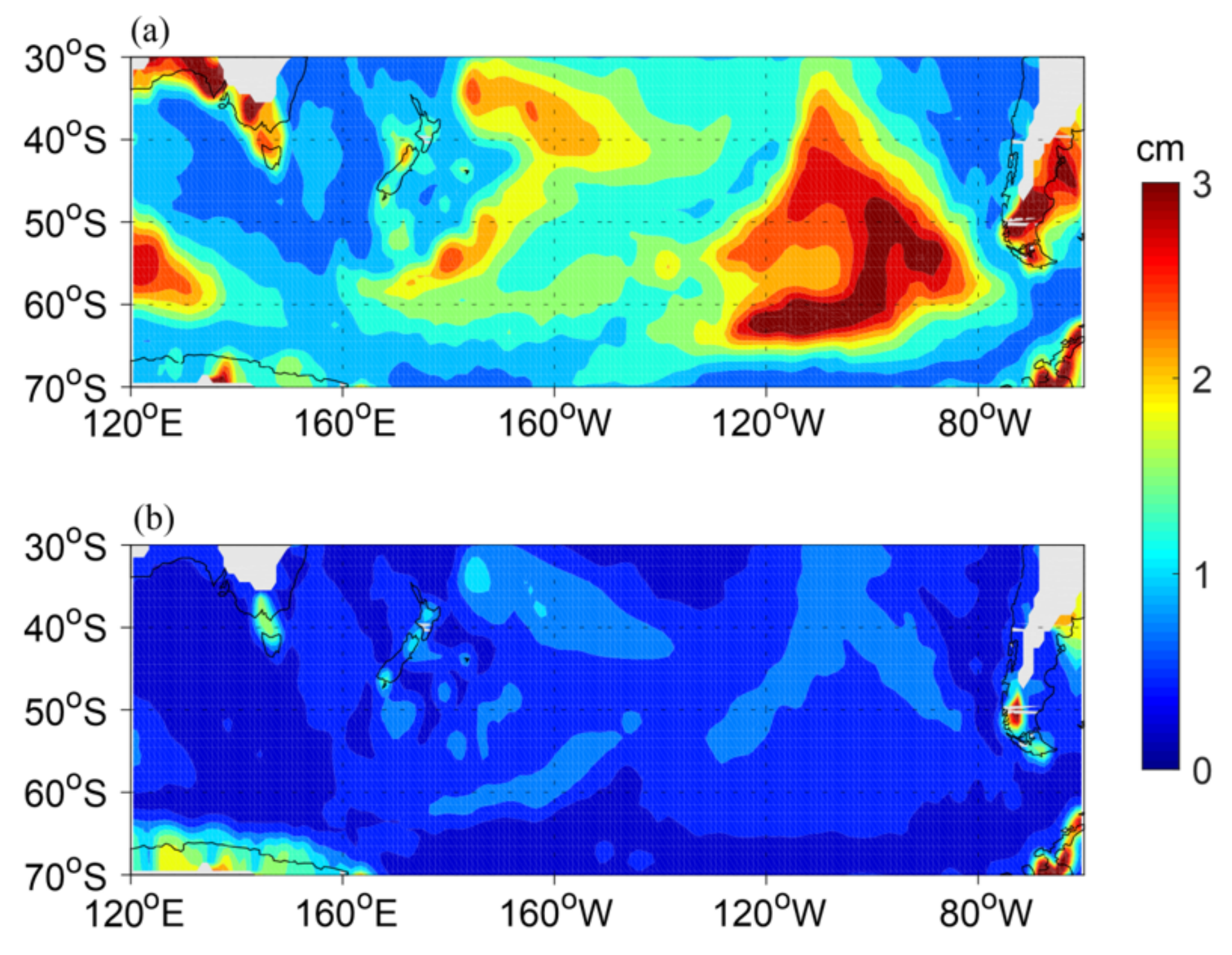

Figure 9

Standard deviation map of PCOM OBP (a) control run and (b) without winds in the South Pacific from 2003 to 2016. 
(a)
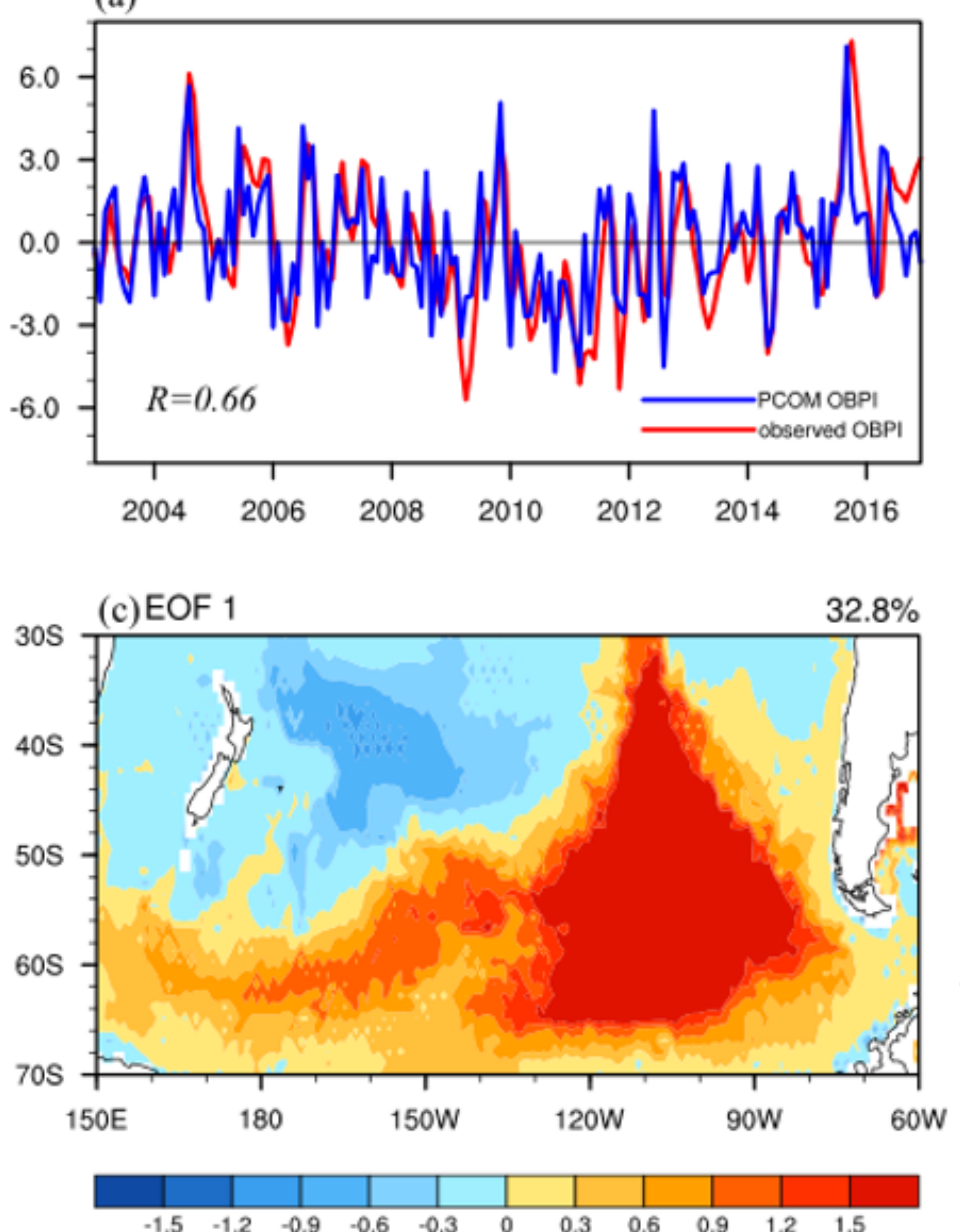

(b)

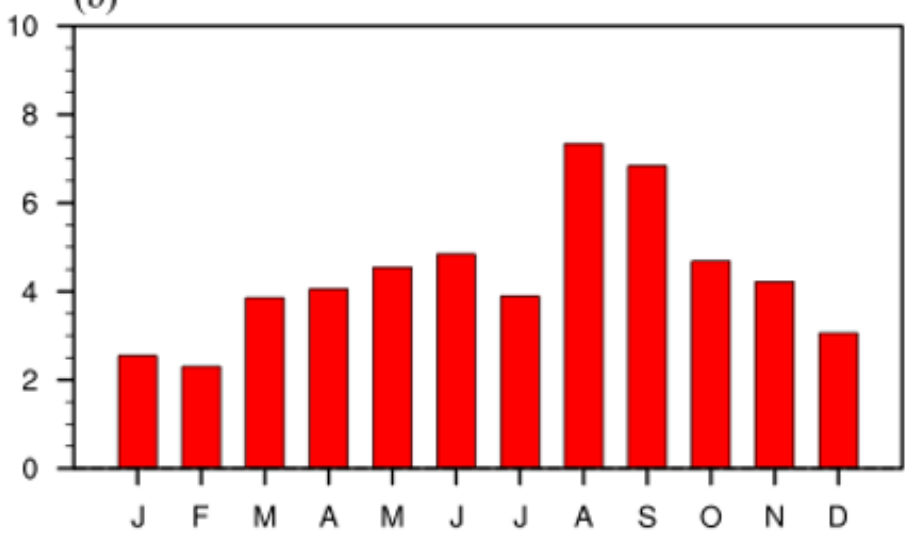

(d) PC 1

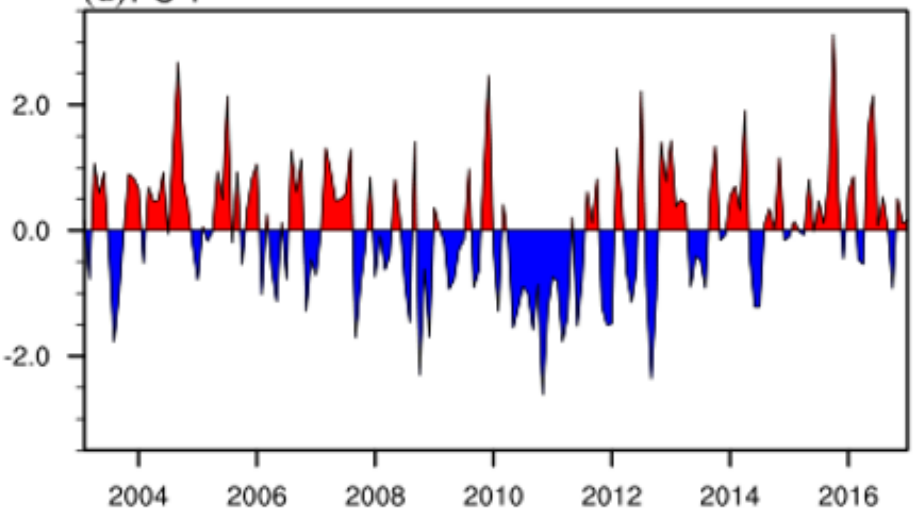

Figure 10

(a) The correlation coefficient between the observed OBPI (red line) and PCOM OBPI (blue line) is 0.66. (b) The climatological seasonal variation of PCOM OBPI, which is the monthly index from 2003 to 2016. (c) Spatial patterns of EOF1 of the monthly PCOM OBP in the South Pacific $\left(70^{\circ} \otimes 30^{\circ} \mathrm{S}, 150^{\circ} \mathrm{E} \otimes 60^{\circ} \mathrm{W}\right)$ for the period 2003-2016 (after removing the monthly mean global average ocean bottom pressure anomalies). (d) is time series of PC1. 
(a) MAMJ

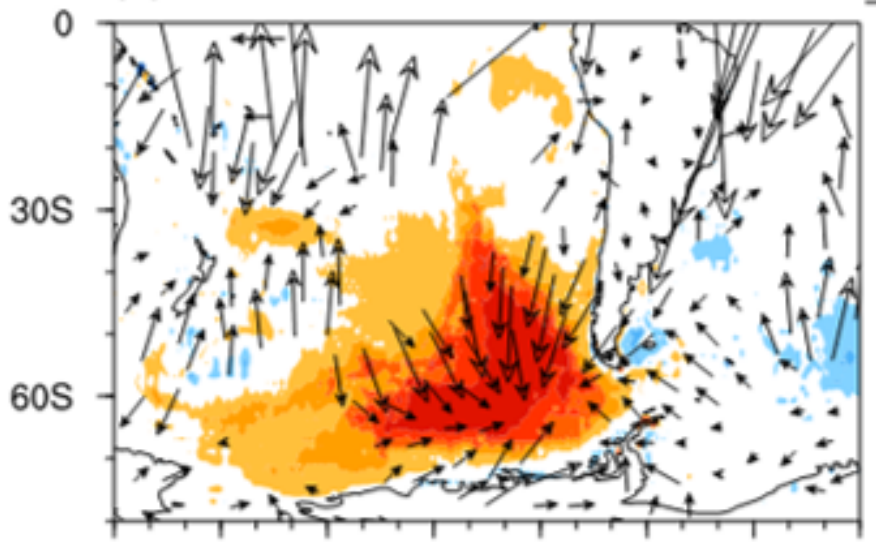

150E $180150 \mathrm{~W} 120 \mathrm{~W} 90 \mathrm{~W} 60 \mathrm{~W} 30 \mathrm{~W}$
$0.1 \quad$ (b) ASON

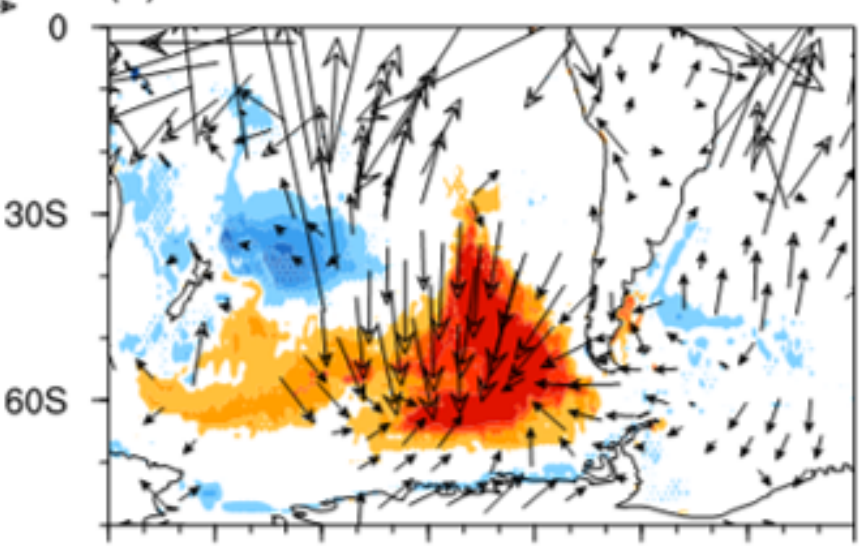

$150 \mathrm{E} 180$ 150W 120W 90W 60W 30W 0

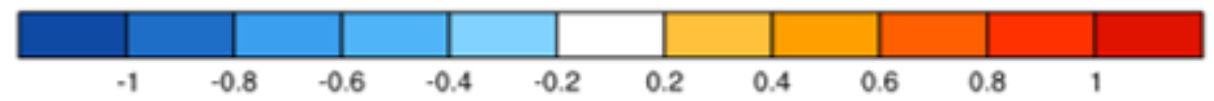

(c) MAMJ

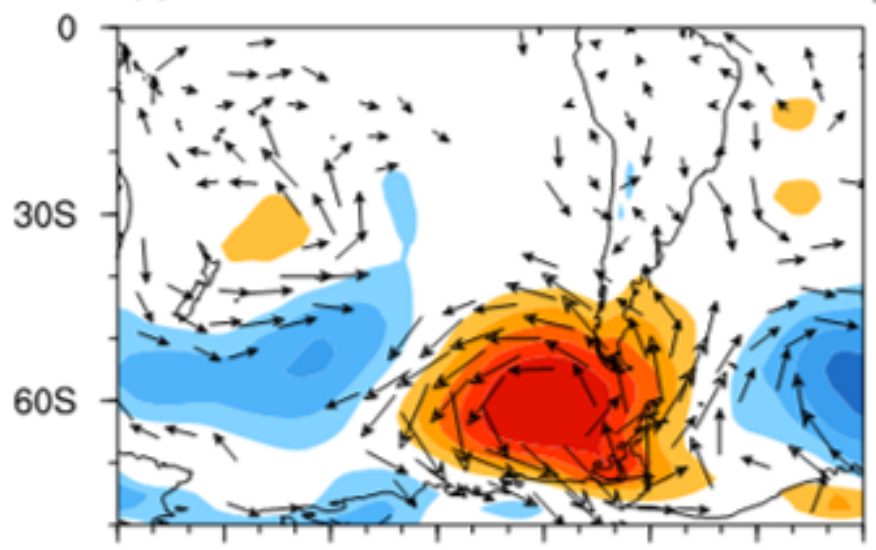

$150 \mathrm{E} 180$ 150W 120W 90W 60W 30W 0 $\stackrel{1}{\longrightarrow}$ (d) ASON

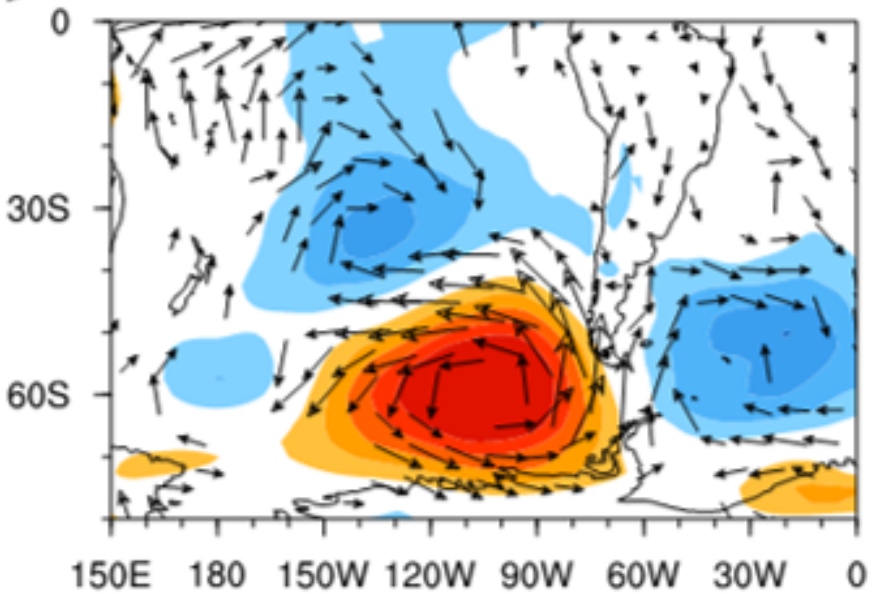

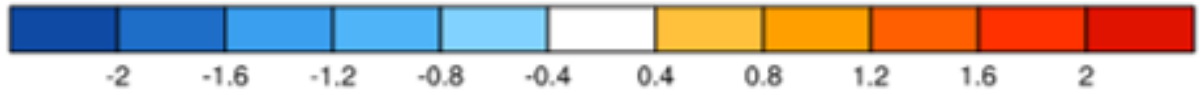

Figure 11

is the same as Fig. 3, but with PCOM OBPI. 


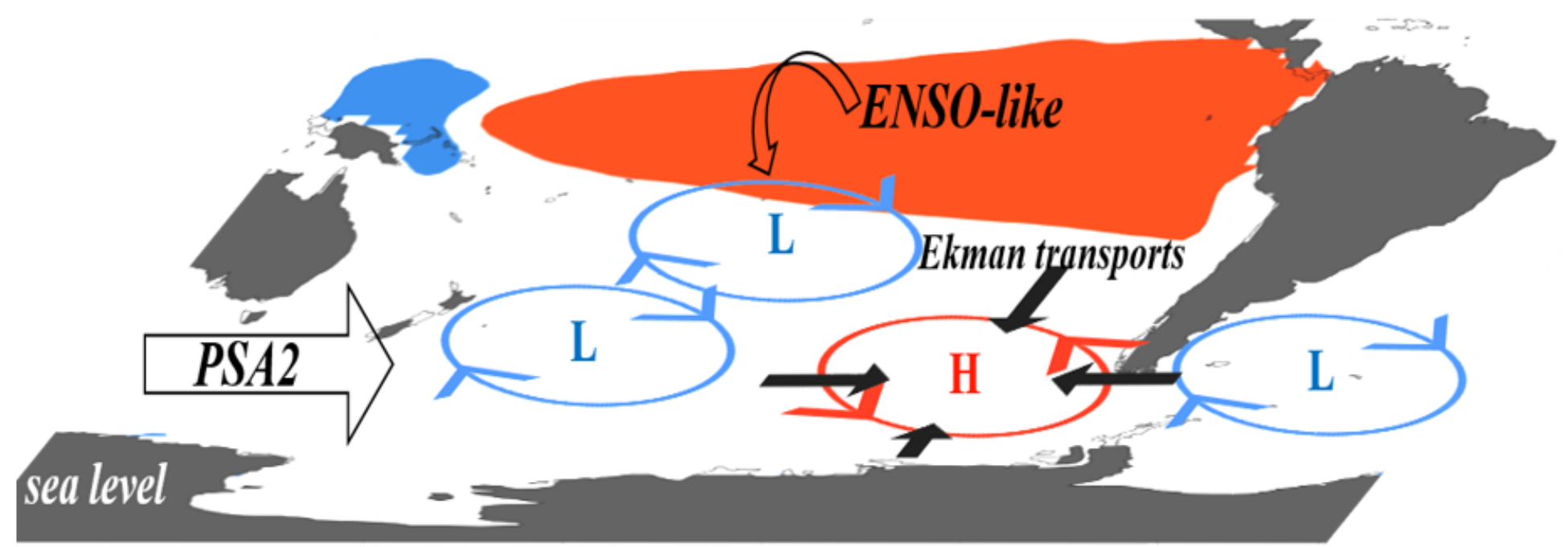

Figure 12

Schematic of the mechanism for the positive OBP variability during austral spring (ASON) and autumn (MAMJ) in the southeastern Pacific. 